\title{
How Understanding-Based Redesign Influences the Pattern of Actions and Effectiveness of Routines
}

\author{
Hari Bapuji ${ }^{1}$ \\ The University of Melbourne \\ Manpreet Hora \\ Georgia Institute of Technology \\ Akbar Saeed \\ Wilfrid Laurier University \\ Scott Turner \\ University of South Carolina
}

\section{Citation:}

Bapuji, H., Hora, M., Saeed, A. and Turner, S., 2018. How Understanding-Based Redesign Influences the Pattern of Actions and Effectiveness of Routines. Journal of Management. DOI: $10.1177 / 0149206317744251$

\section{Acknowledgements:}

We would like to thank Pratima Bansal, Oana Branzei, Kenneth Goh, and Claus Rerup for the many helpful comments they gave on this paper. We would also like to thank the editor Anne Parmigiani, and the two anonymous reviewers for their thoughtful comments. Additionally, this paper has benefited from presentation feedback at the Atlanta Competitive Advantage Conference (ACAC), the Ivey Business School, the Swiss Federal Institute of Technology (ETH Zurich), and the University of Melbourne.

\section{Corresponding author:}

Hari Bapuji, Department of Management \& Marketing, Faculty of Business and Economics, The University of Melbourne, Victoria 3010 Australia

E-mail: hari.bapuji@unimelb.edu.au

\footnotetext{
${ }^{1}$ Corresponding author. All authors contributed equally and are listed in alphabetical order.
} 


\begin{abstract}
Using a novel, mixed methods research design, we examine how understanding-based redesign of a routine influences its effectiveness. By understanding-based redesign, we refer to an intentional change in routine design such that it aligns more closely with the understandings of participants regarding how to perform their roles in the routine. We argue that this type of redesign improves the effectiveness of a routine by facilitating the actions and interactions of routine participants. Our empirical examination focused on manipulating the procedure and physical artifacts available for performing the towel-changing routine at a hotel. Through a field experiment, we found that understanding-based redesign results in greater effectiveness of the routine, and based on a qualitative, interviews-based inquiry with key participants in the routine, we propose six processes by which understanding-based redesign influences participant actions that support routine effectiveness. Our study offers important implications for strategy and organizations research on routines, as well as useful implications for management practice.
\end{abstract}

Key Words: Routine Redesign; Routine Effectiveness; Action in Routines; Artifacts; Sustainability 


\section{HOW UNDERSTANDING-BASED REDESIGN INFLUENCES THE PATTERN OF ACTIONS AND EFFECTIVENESS OF ROUTINES}

Routines are a foundational concept in strategy and organizational theory research (Gavetti \& Levinthal, 2004; March \& Simon, 1958; Nelson \& Winter, 1982). Defined as repetitive, recognizable patterns of actions (Becker, 2004; 2005; Feldman \& Pentland, 2003), routines play an important role in the coordination of firm activities (Grant, 1996; Karim \& Mitchell, 2000), and are widely regarded as the building blocks of organizational capabilities (Parmigiani \& Howard-Grenville, 2011; Salvato \& Rerup, 2011). While firms derive much value from the stability of routines, scholars are increasingly interested in gaining insight into the value that may be gained or lost through the redesign of routines, i.e., intentional change in the formal structure and elements of a routine (Bresman, 2013; Felin, Foss, Heimeriks \& Madsen, 2012; Gupta, Hoopes \& Knott, 2015). Examples of routine redesign include revising formal rules or standard operating procedures (Cyert \& March, 1963; Reynaud, 2005) and changing the artifacts/tools drawn upon during routine performances (Cohen et al., 1996; D'Adderio, 2011; Pentland \& Feldman, 2005).

Strategy and organizations scholars recognize that redesigning routines is often a difficult process that can have disruptive consequences (Helfat, 2003; McGahan \& Mitchell, 2007; Rumelt, Schendel \& Teece, 1994). From the view of routines as memory and coordination (Nelson \& Winter, 1982), scholars have argued that changes to a routine disrupt the established ties among routine participants, impede coordination as participants are less able to anticipate and interpret the actions of one another, and reduce the overall reliability of corresponding firm activities (Cohen \& Bacdayan, 1994; Lazaric \& Denis, 2005; Miller, Pentland \& Choi, 2012). From the view of routines as practice (Parmigiani \& Howard-Grenville, 2011), researchers have also suggested that redesign efforts can be an act of "folly" in that changing formal procedures 
and rules often fails to alter the established pattern of actions and consequently falls short of achieving the intended results (Pentland \& Feldman, 2008). By contrast, other scholars have put forward evidence that routines can be redesigned with beneficial outcomes (e.g., Edmondson, Bohmer \& Pisano, 2001; Salvato, 2009), which Helfat and Peteraf (2003) have described as an act of renewal for firms. In short, while the redesign of routines often has detrimental or ineffectual implications for firms, it may also prove beneficial.

Given that research has shown potential benefits and likely drawbacks associated with redesigning routines, a key challenge for scholars lies in developing better understanding of how redesign influences the effectiveness of routines. This challenge is premised on the idea that "the knowledgeable design and redesign of routines presents a likely lever for those wishing to enhance organizational performance" (Cohen \& Bacdayan, 1994: 554), as well as recognition that our scholarly knowledge of routine redesign is limited (Gupta et al., 2015). Building on these ideas, we suggest that an important avenue for advancing routines research lies in understanding how particular types of redesign are likely to reshape the pattern of actions constituting the routine, and hence influence its effectiveness.

In this study, we develop the concept of understanding-based redesign, and draw on a coordination logic (Becker, 2004) to argue that this type of redesign will increase routine effectiveness. By effectiveness, we refer to the extent to which the routine results in product or service outcomes that achieve the objectives that the organization has for the routine (Cyert \& March, 1963). By understanding-based redesign, we mean an intentional change in routine design such that it aligns more closely with the understandings of participants regarding how to perform their roles in the routine; these understandings are based on the knowledge structures, or schemas, of participants that pertain to such performances (Fiske \& Taylor, 1984). Similar to extant research, understanding-based redesign is based on learning principles; but unlike prior 
work, which has emphasized vicarious learning of best practices from other organizations or organizational units (Bresman, 2013; Szulanski, 1996), understanding-based redesign leverages what routine participants already know regarding activity performance (Levitt \& March, 1988). As a result, understanding-based redesign facilitates the actions of participants, and the interactions among them, leading to increased routine effectiveness.

We expect that understanding-based redesign will be particularly salient for routines in which participants have only limited connections to one another (Feldman \& Rafaeli, 2002), with little if any opportunities for coordination through direct communication. While routines research has tended to examine routines with rich, direct interactions among participants (e.g., Dittrich, Guerard \& Seidl, 2016; Rerup \& Feldman, 2011), Howard-Grenville and Rerup (2017) highlight in a recent review that we have limited scholarly knowledge of the functioning of routines with few connections, if any, and largely indirect interactions among participants. Such features are often found in interface routines, which Nelson (1994) defines as routines that govern the interactions between the employees of an organization (i.e., insiders) and its customers, suppliers, and/or other external parties (i.e., outsiders). While some interface routines can involve notable connections, as in the case of interorganizational routines for alliances (Zollo, Reuer \& Singh, 2002) and repeated partnerships (Holloway \& Parmigiani, 2016), many interface routines are characterized by limited connections, such as routines in service work settings that involve intermittent participation by customers (e.g., Bapuji, Hora \& Saeed, 2012; Leidner, 1993; Pentland \& Reuter, 1994).

Our study empirically examined how understanding-based redesign influences routine effectiveness in such a service setting. Using a novel, mixed methods research design (Creswell, 2014; McGrath, 1995), we examined the towel-changing routine in a hotel, which is performed by housekeeping staff and hotel guests. We began with a field experiment for the purpose of 
theory testing, followed by the use of photo elicitation-based interviews for the purpose of theory elaboration (Lee, Mitchell \& Sablynski, 1999). In addition to its salience as an interface routine, focusing on the towel-changing routine allowed us to concentrate more directly on how understanding-based redesign influences routine effectiveness, given that there are few opportunities for direct interaction and engagement between the housekeeping staff and hotel guests.

Our study makes two complementary contributions to routines research. First, we develop the concept of understanding-based redesign and argue that it improves routine effectiveness by enhancing the pattern of actions that constitutes the routine. We find empirical support for this idea using a field experiment focused on the towel-changing routine in a hotel setting. This advances the literature with respect to how a particular type of redesign influences routine effectiveness, and responds to calls for greater attention to microfoundations of routines and capabilities (Felin et al., 2015; Salvato \& Rerup, 2011) and greater adoption of field experiment methodology in strategy and organizations research, particularly as a way to deal with the challenges of endogeneity (Chatterji, Findley, Jensen, Meier \& Nielsen, 2016; Hamilton \& Nickerson, 2003). Second, through a qualitative, interviews-based inquiry, we offer further insight into understanding-based redesign by explicating six processes through which design and artifacts shape the patterns of actions and interactions constituting routines (D'Adderio, 2011; Parmigiani \& Howard-Grenville, 2011). This responds to calls by scholars for greater attention to the interactions between individuals and artifacts in routines (Feldman et al., 2016; Felin et al., 2012), and in particular, it extends theory regarding how artifacts influence the actions of participants in interface routines (Howard-Grenville \& Rerup, 2017). Overall, these contributions to the routines literature are part of a larger effort to integrate macro and micro approaches to organizational research (Aguinis, Boyd, Pierce \& Short, 2011; Salvato \& Rerup, 2011), and 
illustrate how such integrative research can generate actionable insights for practitioners.

The remainder of the paper is organized as follows. First, we present a brief review of the literature on routine redesign and effectiveness, particularly focusing on the tension between stability and change as sources of routine effectiveness. This is followed by our argument for how understanding-based redesign improves routine effectiveness. We then discuss the empirical setting, methodologies, and results. We conclude with implications for routines research in strategy and organizational theory, as well as implications for management practice.

\section{THEORY}

\section{Routine Stability, Redesign, and Effectiveness}

A common view among strategy and organizations scholars is that firms derive considerable value from the stability of routines, e.g., routines as organizational memory (Argote, 2013; Becker, 2004; Nelson \& Winter, 1982). Stable patterns of interdependent actions provide a learning foundation for routine participants, enabling them to develop insight into their own role in the routine, and establish expectations regarding the actions of other participants (Dionysiou \& Tsoukas, 2013; Howard-Grenville, 2005). In turn, the stability of routines contributes to effectiveness in performing organizational activities, as participants can increasingly rely on these insights and expectations to guide their actions and coordinate their interactions (Becker, 2004; Camerer \& Knez, 1996). In empirical work, scholars have found evidence that such stability contributes to routine effectiveness, particularly under stable environmental conditions (Argote, 1982; Cohen \& Bacdayan, 1994; Danner-Schröder \& Geiger, 2016; Turner \& Rindova, 2012).

From this view, change in the design of a routine reduces its effectiveness, as change disrupts the established pattern of actions, and impedes coordination because participants are less able to understand their own roles, and reliably anticipate and interpret the actions of other 
participants (Baum \& Shipilov, 2006; Cohen \& Bacdayan, 1994). From a similar view, routines scholars working from a practice perspective have argued that organizations often invest considerable resources in changing the formal design of a routine, yet the changes fail to alter the pattern of actions and achieve the desired outcomes (Feldman, 2003; Pentland \& Feldman, 2008). In fact, much of the research in strategy on changing routines is based on the principle of vicarious learning, i.e., adopting practices that have been proven to be superior in other settings (Maritan \& Brush, 2003; Szulanski, 1996), rather than trying to redesign or rework a routine (Darr, Argote \& Epple, 1995). Research on replication strategy, i.e., growth through replicating routines in new settings, is also based on a similar principle. Because it can be difficult to improve certain elements of a routine without negatively impacting others, particularly when the routine is causally ambiguous (Lippman \& Rumelt, 1982), firms are likely to perform better with replication (i.e., copy exactly), rather than with adaptation of the routine to local conditions (Winter, Szulanski, Ringov \& Jensen, 2012). In short, this research underscores the importance of routine stability and points to the challenges of attaining greater routine effectiveness through redesign.

In contrast to this work emphasizing the detrimental or ineffectual implications of routine redesign, scholars have also argued that changing the design of a routine can increase its effectiveness (Edmondson et al., 2001; Salvato, 2009). This work emphasizes the value of innovation and adaptation, and recognizes that redesigning routines can be a source of renewal for organizations (Helfat \& Peteraf, 2003). From this perspective, firms can increase the effectiveness of routines by changing them to incorporate lessons from experiential learning (Levitt \& March, 1988; Rerup \& Feldman, 2011), modifying them based on ideas obtained through vicarious learning (Bresman, 2013), or altering them based on forward-looking assessments of likely consequences, i.e., off-line learning (Gavetti \& Levinthal, 2000). In 
addition, firms can redesign routines to take advantage of new productivity-enhancing tools (Cacciatori, 2012; Edmondson et al., 2001), or to respond to changes in the surrounding environment (Sastry, 1997). In short, this learning-based stream of research suggests that redesigning a routine can increase its effectiveness.

In line with these contrasting arguments, scholars have provided empirical evidence in support of detrimental and beneficial effects of routine redesign. From the detrimental view, in a lab setting, Cohen and Bacdayan (1994) found that a change in the formal rules for playing a routinized game resulted in slower task performance. In field research, Gupta et al. (2015) found evidence that the redesign of a routine for producing signs and banners resulted in failure, specifically by failing to meet the sales and profitability objectives of management. And in related work in the context of office services franchises, scholars have found that change in routine design, relative to the design recommended by the franchisor, resulted in greater risk of franchise outlet failure (Winter et al., 2012). By contrast, routines scholars have also put forward evidence in support of beneficial effects from the redesign of routines. In a mixed methods study of pizza franchises, Darr et al. (1995) provided qualitative evidence of two redesigns resulting in greater routine effectiveness: one focused on redesigning the routine for making pizzas by changing the method for pepperoni placement, and one focused on redesigning the larger production routine by changing the boxing procedure. Similarly, in a multiple case study of hospitals, Edmondson et al. (2001) examined the redesign of cardiac surgery routines based on incorporating a new technology, finding that redesign was successful when operating room teams engaged in a particular learning and adjustment process that enabled the redesign to become ongoing practice. And in field research examining ISO-based redesign of routines in a meat-processing company, Lazaric and Denis (2005) found that redesign resulted in improved outcomes (e.g., reduction in bacterial contamination). 
These contrasting accounts regarding the benefits of stability versus change in routine design point to the need for a closer examination into how particular changes in the design of a routine influence its effectiveness. In considering this question, we take into account the routines research that describes how participants frequently perform their roles in ways that are not consistent with the formal design of the routine, i.e., the prescribed pattern of actions, which can result in coordination problems (Cohen et al. 1996; Pentland \& Feldman, 2005, 2008). ${ }^{1}$ This situation may arise when the routine design calls for participants to perform their roles in ways that do not align with how they understand the activities to be performed (Feldman, 2003). This implies that redesigning a routine to better align with participants' understandings of how to perform the activities might result in greater effectiveness. In the next section, we build on this insight to suggest that understanding-based redesign will improve routine effectiveness by enhancing the actions and interactions in a routine.

\section{Understanding-Based Redesign and Routine Effectiveness}

Understanding-based redesign refers to a particular type of routine redesign that involves changing the formal structure and elements of a routine (e.g., rules, tools), such that participants are called upon to act in ways that more closely align with their understandings of how to perform their roles. These understandings are based on routine participants' related schemas, which are knowledge structures that organize experiences pertaining to performing their role in the routine (Fiske \& Taylor, 1984). This conceptualization recognizes that artifacts like formal procedures, rules, and tools can be key enablers of change in routines (Bapuji et al., 2012; Cohen et al., 1996; D'Adderio, 2011), and emphasizes the need for identifying the type of change in the routine design, i.e., the nature of change in the formal structure or elements, under study.

Drawing on the innovation studies literature, we propose that understanding-based redesign represents an incremental innovation to the routine design, which leverages the existing 
knowledge of routine participants regarding the corresponding activity, and introduces a limited amount of new knowledge (Banbury \& Mitchell, 1995; Dewar \& Dutton, 1986). By contrast, many routine redesigns can be viewed as radical innovations, in that participants are called to act in new ways that are fundamentally different from how they understand an activity to be performed and therefore exemplify "revolutionary changes" and "clear departures from existing practice" (Dewar \& Dutton, 1986: 1422). The concept of understanding-based redesign is also consistent with the idea of exploiting existing knowledge while incorporating some new knowledge, as described in the literature on organizational learning (March, 1991).

Building on these ideas, we argue that redesigning a routine to leverage the existing understandings of routine participants will increase its effectiveness. ${ }^{2}$ For one, understandingbased redesign is well-poised to change the established pattern of actions. From the view of routines as institutions (Nelson \& Sampat, 2001), there are often considerable challenges associated with changing the taken-for-granted nature of routines, particularly when a routine has become standardized across organizations, e.g., a routine that is common throughout an industry (Nelson, 1994). To overcome the challenges associated with institutional change, Nelson and colleagues argue that the routine may be modified in such a way that it is consistent with other institutions, so that participants perceive the new way of acting as legitimate, even though it is different relative to the extant routine (Nelson \& Sampat, 2001; Nelson \& Nelson, 2002). ${ }^{3}$

Understanding-based redesign also provides participants with greater clarity regarding how they should perform their roles in the routine, as well as a better sense of which tools/artifacts will help them to more successfully accomplish their objectives. This heightened clarity results from redesigning the routine in ways that build upon participants' existing frames, knowledge, and expectations (Leonardi \& Barley, 2010). Further, when participants’ understandings of the activities are based on direct experience in other settings (Levitt \& March, 
1988), they can leverage, at least in part, established habits for role performance that are based in procedural memory (Cohen, 2007).

In addition to facilitating the actions of individual participants, understanding-based redesign also enhances the interactions among them. When a routine is redesigned such that the called-for actions align more closely with participants' understandings of their roles, participants are likely to have greater shared knowledge regarding the performance of the routine. Through greater shared knowledge, participants are able to form more reliable expectations about the actions of others, and accordingly, they are able to better predict how other participants will perform their roles (Cohen et al., 1996; Dionysiou \& Tsoukas, 2013; Grant, 1996).

Consequently, this provides a more stable foundation for the pattern of actions that constitutes the routine, helps to facilitate the coordination among routine participants, and thereby reduces the likelihood of problems arising from the exchanges among them.

In sum, we argue that understanding-based redesign facilitates the actions of routine participants by leveraging their knowledge of how to perform the actions, and enhances the interactions among routine participants by helping them to form more reliable expectations of the actions of one another. Accordingly, we hypothesize that understanding-based redesign of a routine will increase its effectiveness.

\section{METHODS AND FINDINGS}

To examine how understanding-based redesign influences routine effectiveness, we sought a setting in which understanding-based redesign would be particularly salient. Following prior research that has examined service-based interface routines involving customers (e.g., Leidner, 1993), we focused on an interface routine in the hotel/lodging industry, which involved participation by hotel employees and customers. Specifically, we focused on the towel-changing procedure, in which "hotels commonly tell guests to leave towels on the floor or in the tub when 
they want fresh ones, or fold and hang them on the towel rack when they do not" (American Hotel \& Lodging Association, 2016). Our focus on the towel-changing routine in a hotel setting is part of a larger project examining the actions and interactions that influence the emergence, performance, and outcomes of routines (Bapuji et al., 2012; Joshi, Bapuji \& Chandrasekhar, 2013).

Our study site was "Pleasant Stay Hotel” (PSH), a small independently-operated hotel with 48 guestrooms and suites. Situated in exclusive and scenic surroundings, PSH is located in a Canadian city - close to a university, a research park, and a hospital, and the majority of its guests are repeat patrons. The guests at PSH were informed of the towel-changing routine by means of a sign on the bathroom counter that read: "Save Our Planet. Dear Guests: Every day, millions of gallons of water are used to wash towels that have been used only once. You make the choice: A towel on the towel rack means 'I will use again.' A towel in the bathtub means 'Please exchange.' Please decide for yourself. Thank you for helping us to conserve the Earth's vital resources." By outlining the procedure, the sign attempts to align the actions of guests and housekeeping staff, so that problems of coordination and miscommunication between them can be avoided, and routine objectives can be achieved (Grant, 1996).

The towel-changing routine is suitable for our study because it is an interface routine, characterized as a repetitive, recognizable pattern of interdependent actions carried out by organizational members and outsiders (Feldman \& Pentland, 2003; Nelson, 1994). Specifically, the actions follow a recognizable pattern in which guests leave towels in particular locations, and housekeeping staff respond to those actions (e.g., leaving the towel for reuse, vs. collecting it for laundering). The actions are repetitive because they are repeated every day during the guest stay period, in addition to being repeated across guest stays in PSH, and across stays in hotels more generally, given that the towel-changing routine is a common practice in North America 
(American Hotel \& Lodging Association, 2016). Also, they are interdependent because housekeeping staff cannot perform their actions without the actions of guests, and vice-versa.

Additionally, the towel-changing routine was appropriate for studying the effectiveness of understanding-based redesign because PSH had a clear objective for the routine: to reduce the replacement of towels. While this is implied in the sign, hotel management also confirmed that reduction in towel usage helped decrease costs, and reduced strain on housekeeping staff. The presence of a clear objective enabled us to objectively measure the influence of understandingbased redesign on routine effectiveness by examining towel usage by guests. Further, as the routine rarely involved direct verbal communication between the guests and housekeeping staff to help clarify the actions of one another, it allowed us an opportunity to concentrate our study more closely on how the actions of participants were influenced by the redesign.

Conducting our study with a focus on this simple, common routine in an independentlyoperated hotel provided two key advantages that helped us overcome typical challenges faced by scholars who empirically study routines. First, the simplicity of the routine helped us to address many of the methodological challenges associated with studying routines and their changes, such as difficulties in identification that stem from limited observability and subjectivity in the descriptions of routines (Becker, Lazaric, Nelson \& Winter, 2005). The towel-changing routine facilitated identification by allowing for triangulation across data sources, including direct observation, interviews, and documentation of performances/outcomes by housekeepers. Second, the routine lent itself well to being manipulated in a field experiment, which afforded the benefits of experimental control and helped in isolating potentially confounding factors, while also promoting realism of conditions for study participants (McGrath, 1995); the opportunity to examine the routine in realistic conditions is important because routines tend to exhibit contextual specificity (Helfat \& Karim, 2014). Moreover, the experimental manipulation for our 
study ensured that as new elements were introduced into the redesigned routine, there was minimal distortion in the activities of the housekeeping operation at PSH.

Our research design used a novel, mixed methods approach (Creswell, 2014). We began the study with a familiarization stage to develop deep understanding of how the towel-changing routine operated. Based on insights gleaned from this stage, we designed and conducted a field experiment to test the impact of understanding-based redesign on the effectiveness of the towelchanging routine. Our redesign involved changes in the formal procedure and artifacts available for performing the routine. More specifically, redesign was reflected in changes in the procedure that guides performance of the routine, and in the physical artifacts that participants can draw upon while performing their roles. We then conducted semi-structured interviews with hotel guests using a photo-elicitation technique as a complementary methodology, which enabled us to elaborate our initial theory with respect to how understanding-based redesign influences the pattern of actions constituting the routine, and thus enhances routine effectiveness.

\section{Familiarization Stage}

During the familiarization stage, we mapped the towel-changing routine at $\mathrm{PSH}$ to identify its main activities and gain insight into how the routine might be redesigned to leverage the understandings of routine participants. To facilitate our mapping of the towel-changing routine, we (i) conducted interviews with three managers at PSH (front office manager, housekeeping manager, and general manager), (ii) observed/shadowed the housekeeping staff for three daily shifts, and (iii) followed that up with interviews with two housekeepers.

During our observations, we noted that guests left used towels in various locations in the bathroom (e.g., in or on the bathtub, on the rack, on the vanity, on the floor, over the shower rod, hanging on the hook). Towels were also found in the bedroom (e.g., on the bed, on a chair, on the TV counter). The staff confirmed that finding towels strewn about the room was common 
and that these towels were picked up for laundering. After performing their regular housekeeping activities, if all towels were used, the staff placed four fresh bath towels on a towel rack in the bathroom. If only two towels were used and two towels seemed untouched on the rack, the staff left the unused ones as they were, and placed two additional fresh towels on the rack.

When we asked the housekeeping staff about their role/decisions in the towel-changing routine, particularly with respect to towel replacement, one employee said, "We probably change every towel." Another said, "If the towel is on the floor, that's how you decide [to replace it]; if [the towels] are hanging up, I don't know, just use your discretion ... [change it] if it's wet or it's touched." These statements, together with our personal observation of towels being strewn about the room, highlighted that divergence existed in how the routine was being performed. This divergence was evident across various performances of the towel-changing routine, and in relation to how management intended for the routine to be performed. ${ }^{4}$

The familiarization stage revealed several core actions in the towel-changing routine: (1) guests make use of one or more fresh towels, (2) guests leave the used towel(s) in particular locations around the hotel room (e.g., in the bathtub, on the bed), (3) housekeeping staff determine which towels to collect from the room for laundering, and (4) as needed, housekeeping staff replace fresh towels on the towel rack. Thus, the routine involves multiple actors (i.e., guests and housekeepers) and artifacts, including the towel itself, the various locations in which it might be deposited (e.g., the towel rack, bed), and the sign on the counter. We view the towel as the focal artifact in the interactions between guests and housekeepers, the objects upon which the towel might be deposited as supporting artifacts (Nicolini, Mengis \& Swan, 2012), and the sign as a representational artifact (D’Adderio, 2011) that outlines the procedure for towel changing.

\section{Field Experiment}


To test whether an understanding-based redesign would result in greater effectiveness of the towel-changing routine, we ran a field experiment, which enables "transplanting the typical laboratory experiment into the field, making adjustments that capitalize on the richness of the naturalistic environments in which they occur" (Greenberg \& Tomlinson, 2004: 705). This type of experiment allows researchers to divide sampling units into treatment and control groups in a natural setting (Harrison \& List, 2004).

For the experiment, we assigned treatment and control conditions based on floors of the hotel. PSH had three floors, but guestrooms were spread mainly over the upper two floors. We randomly designated one of the upper floors as the control group and the other as the treatment group. The rooms on the control group floor maintained the extant design for the towel-changing routine, i.e., asking guests to place a used towel on the towel rack if they intended to reuse it, or leave it in the bathtub to have it replaced. For the treatment condition, we redesigned the routine by modifying key elements in a way that we expected would be consistent with guests' understanding of how to perform their roles; specifically, we introduced a wicker basket to deposit towels for replacement, and identified the bathroom door hook to leave towels for reuse.

We reasoned that a wicker basket would leverage what guests already know about where to leave used towels for washing because many people have such a bin in their homes for depositing dirty laundry. To formally examine this reasoning, we conducted a survey with 64 students (50 masters, 14 undergraduates), where students were shown a picture of the wicker basket in the bathroom at PSH and asked to indicate with open responses what the object was and/or what it was intended for. The large majority (78\%) of respondents identified the wicker basket as something that would be used for laundry or towels, which supported our choice of redesign. We could not find an artifact that would easily blend into the hotel décor to leverage guests' understanding about leaving towels they would reuse; in addition, hotel management was 
reluctant to allow us to introduce another artifact in the hotel room. Therefore, we opted to designate a pre-existing bathroom door hook as the place to hang towels for reuse, recognizing that such hooks are common for hanging towels in other settings (e.g., homes) and thus guests would be more inclined to understand those as appropriate locations to leave towels for reuse. In other words, we expected that guests would easily see the basket and hook as tools for replacement and reuse, and accordingly have a better understanding of how to perform the actions expected of them in the towel-changing routine. Accordingly, we revised the sign in the treatment group to outline the redesigned towel-changing procedure, while we used the preexisting sign for the rooms on the control group floor. The photos in Figures $1 \mathrm{a}$ and $1 \mathrm{~b}$ illustrate the control and treatment group settings.

\section{Please insert Figures $1 \mathrm{a}$ and $1 \mathrm{~b}$ about here}

Data collection for the field experiment. We conducted the field experiment over a four-week period to capture the actions of routine participants as well as routine effectiveness. ${ }^{5}$ Following Goldstein, Cialdini \& Griskevicius (2008), we enlisted the help of the housekeepers to collect the data on the number of towels that guests left on various artifacts in the bathroom -including the towel rack, bathtub, shower-curtain rod, bathroom door, and bathroom door hook, as well as the towels that were left outside the bathroom. For the treatment group, data was also collected on the number of towels placed in the wicker basket. Further, in both the treatment and control groups, the housekeepers recorded the number of towels replaced in each room.

As part of the hotel's existing practice, the housekeeping staff already used a form to report the number of towels replaced in each room. We modified this form slightly to include information on the locations where the towels were found, and we then trained the housekeeping staff to properly fill them out. Since the housekeeping staff were involved in the performance of 
the routine, we did not inform them of the purpose of the study. Instead, we mentioned that this data was being collected for a $\mathrm{PhD}$ thesis that examined the behaviour of hotel guests. We consciously avoided the presence of management when we interacted with the housekeepers since the presence of higher-ups had the potential to signal that the hotel had a stake in the study or that the job performance of the housekeepers was somehow being monitored or evaluated.

Towel location and replacement data was only collected for those guests who stayed for at least two nights since the question of reuse was not relevant for a single-night stay. Also, we excluded data from checkout days because all towels are replaced at the end of each stay irrespective of where they are left. Our data consisted of 177 observations (177 guest days), of which 91 observations were from the treatment group and 86 were from the control group.

The random assignment of floors to control and treatment groups, and guests to those floors, was expected to mitigate any confounding factors. However, to confirm the same, we checked whether there was any difference between the groups in terms of the length of stay, and the number of guests in a room per stay. The t-test of the average lengths of stays showed no significant difference between the treatment group and the control group (3.07 days vs. 3.08 days, $\Delta=-0.01, n . s$.$) . Also, there was no significant difference in the number of guests in a room$ per stay between the treatment and the control groups (1.55 guests vs. 1.33 guests, $\Delta=0.22$, n.s.).

Data analysis and findings from the field experiment. Based on the idea that the redesigned routine would be more consistent with guests' understanding of how to perform the actions in the towel-changing routine, we expected that the actions of guests in the treatment group would differ in particular ways (described below) and result in greater effectiveness. Accordingly, we ran a series of t-tests to examine the corresponding differences between the treatment and control groups. Since the numbers of guests varied between both groups, and among rooms within each group, we normalized the guest days by the respective numbers of 
guests registered for each stay.

First, we examined whether the actions of treatment group guests differed from those of control group guests. Specifically, we expected that the actions of treatment group guests would differ in such a way that (i) they would leave fewer used towels in the bathtub, and they would be inclined to leave them in the basket, and (ii) they would leave fewer used towels in nondesignated locations (i.e., those locations not designated in the extant or redesigned procedure locations other than the tub, rack, basket, and hook). Consistent with our expectations, we found that the guests in the treatment group deposited on average 0.23 bath towels in the bathtub, significantly fewer than the guests in the control group that deposited 0.52 bath towels $(\Delta=-0.29$, $p<0.001)$. Further, guests in the treatment group deposited an average of 0.25 bath towels in the basket, which was significantly different from zero $(p<0.001)$ and higher than the average number of bath towels left by treatment group guests in any other place. Also, we found that guests in the treatment group left an average of 0.19 towels in non-designated locations, whereas guests in the control group left an average of 0.38 towels in such locations $(\Delta=-0.19, p<0.05)$.

Second, we examined whether the routine in the treatment group was more effective, i.e., fewer towel replacements compared to the control group. Consistent with our expectation, we found that an average of 0.99 towels were replaced by housekeepers per day in the treatment group, which was significantly lower than the 1.37 towels that were replaced in the control group $(\Delta=-0.38, p<0.01)$.

The results above support the idea that redesign of the towel-changing routine in the treatment group yielded a different pattern of actions, and also improved routine effectiveness. Next, in accordance with recent research examining the dynamic effects associated with routines and capabilities (e.g., Martin \& Helfat, 2015; Parmigiani \& Howard-Grenville, 2011; Turner, Mitchell \& Bettis, 2013), we extended our analyses to better understand the mechanism(s) 
through which the redesign influenced routine effectiveness by considering the dynamic nature of the corresponding effects (Carbon \& Leder, 2005; Ployhart \& Vandenberg, 2010).

Extending analyses. Taking advantage of the longitudinal structure of the data, our extending analyses examined the initial and subsequent effects of routine redesign. For this, we split the observations into two categories: (a) an "initial day" set, which included the guest days that followed the first night, and (b) a "subsequent days" set, which included all the remaining guest days (e.g., the day after the second night, the day after the third night, and so on). Based on the simplicity of the towel-changing routine, we expected that any learning-based effects would develop relatively quickly. Therefore, we focused our attention on comparing the initial effect (using the set of initial day observations) to the subsequent effect (using the set of subsequent days observations). Moreover, this split of the data provided a roughly equivalent number of observations, which was beneficial for comparing the results of our empirical tests. Our corresponding examination was based on between- and within-group analysis, and the results are presented in Tables 1a-c.

\section{Please insert Tables 1a-c about here}

The extending analyses provided two interesting insights. First, the results showed that the effectiveness of understanding-based redesign develops over time. Specifically, as presented in Table 1a, there was no statistical difference in the number of towels replaced in the control and treatment groups on the initial day $(\Delta=0.07$, n.s. $)$. But, significantly fewer towels were replaced in the treatment group on subsequent days $(\Delta=-0.71, p<0.001)$. Further, towel replacement increased within the control group from the initial day to the subsequent days $(\Delta=0.69, p<0.001)$, but no such change occurred in the treatment group $(\Delta=-0.09$, n.s. $)$. Second, the above noted degradation in the control group and maintenance in the 
treatment group aligned with a combination of guest actions pertaining to leaving towels in the bathtub and in the non-designated locations. Our initial analyses pointed to two ways in which redesign may have influenced routine effectiveness by altering the ways in which guests indicated their desire for towel replacement/reuse: (1) fewer towels left in the bathtub in favor of the basket, and (2) fewer towels left in non-designated locations. Results from the extending analyses suggest that guest actions with respect to leaving towels in non-designated locations was the key contributor to improved routine effectiveness in the treatment group. As presented in Table $1 \mathrm{~b}$, the results showed an immediate impact in the actions of treatment group guests with respect to use of the bathtub, which persisted into the subsequent days: guests in the treatment group left fewer towels in the bathtub than control group guests did on the initial day $(\Delta=-0.33$, $p<0.001)$, and on subsequent days $(\Delta=-0.26, p<0.01)$; further, the change in usage of the bathtub from the initial day to the subsequent days was not significant in either group. Similarly, there was significant use of the basket by the treatment group guests, both on the initial day and on subsequent days $(p<0.001)$, but there was no significant change in the use of the basket from the initial day to the subsequent days.

As presented in Table 1c, there was no significant difference in the number of towels left in non-designated locations by guests in the treatment and control groups on the initial day $(\Delta=0.00$, n.s.). On subsequent days, however, treatment group guests left fewer towels in nondesignated locations than control group guests did $(\Delta=-0.34, p<0.05)$. More notably, treatment group guests left fewer towels in non-designated locations in the subsequent days than they did on the initial day $(\Delta=-0.25, p<0.05)$. In contrast, although not statistically significant, control group guests left more towels in non-designated locations on subsequent days than on the initial day $(\Delta=0.09$, n.s $)$.

Overall, the temporal pattern of the results reveal that the change in effectiveness 
corresponded to changes in guests' behavior regarding leaving towels in non-designated locations, rather than their use of the bathtub/basket. This suggests that redesign of the towelchanging routine resulted in greater effectiveness (reflected in fewer towels being replaced) by making the reuse intentions of guests clearer to housekeepers, so that there were fewer instances in which housekeepers replaced towels left in non-designated locations, such as those hung on the shower rod or over the bathroom door. In other words, actions of treatment group guests likely reduced uncertainty for housekeepers and thus increased routine effectiveness.

In sum, the results of the field experiment indicate that an understanding-based redesign of the towel-changing routine increases its effectiveness, by facilitating the actions and interactions of routine participants. While these findings align with our expectations, they do not reveal how understanding-based routine redesign leverages participants' understandings to influence their actions and improve routine effectiveness. Therefore, as the final stage of our mixed methods study, we conducted semi-structured interviews with hotel guests to better understand the means through which the redesign influenced the actions of guests. Based on the findings from these interviews, we elaborate upon our initial theory by proposing a model of how understanding-based redesign influences participant actions in ways that support routine effectiveness.

\section{Photo-Elicitation Interviews}

Design of interviewing process and data collection. We used an interview protocol to maintain the rigor and reliability of the data collection process. The protocol included the photoelicitation interview technique, which involves "inserting a photograph into a research interview" (Harper, 2002: 13). In particular, we used the auto-driving approach, "whereby interviews are 'driven' by the interviewees who discuss the photos they have taken and/or are viewing" (Parker, 2009: 1118). For the photo-elicitation interview technique, we used photographs depicting the 
treatment and control group settings in the field experiment at PSH (similar to Fig. 1a and 1b).

We contacted PSH guests to request their participation in our interviews by way of an invitation letter shared with the guests by hotel staff at check-in. We interviewed the guests who agreed by first providing some general background on the towel-changing routine without going into the specifics of the study. We then showed the guests a set of photographs (similar to those in Figure 1a) that revealed the control group routine (e.g., towel rack for reusing towels, bathtub for replacing towels, and the sign depicting the routine). In particular, we asked the interviewees what the depicted setting meant to them, how they would act in the routine, and what would prompt this behavior. Next, we showed the guests a second set of photographs (similar to those in Figure 1b) related to the treatment group routine (e.g., bathroom door hook for reusing towels, wicker basket for replacing towels, and the sign) and repeated the same questions posed earlier. We also asked them to compare their actions in the two settings and elaborate why their behavior might be different between them.

Since the interviewees were hotel guests at PSH during the time of the interviews, they immediately related to the settings we presented in the photographs and readily offered responses revealing their actions. For example, on seeing the photographs of the control setting, the guests frequently commented, "looks familiar." Some guests recounted their experiences, such as "I actually had, this morning, thought about where would I put it [the used towel] in the towel rack." These statements suggest that the photo-elicitation approach was effective in triggering reactions and responses to the settings that were used in the experiment (Parker, 2009).

We conducted interviews with 17 PSH guests, after which we felt as though we had reached theoretical saturation (Eisenhardt, 1989). The interviews varied in length from 15 minutes to 30 minutes. We recorded the interviews of 15 guests, who consented to recording, and transcribed them within 48 hours. For the remaining two guests, who did not consent to having 
their interviews recorded, we made notes during and following the interviews.

The guests we interviewed at PSH were not participants in the field experiment. We could not directly interview the field experiment participants due to operational challenges given the nature of the routine and because management wanted to ensure minimal disruption for hotel guests. One advantage of this approach is that it helped to establish a common frame of reference for the interviewees, rather than having variability in preceding conditions (e.g., some interviewees exposed to control group conditions, while others exposed to treatment group conditions). Further, this approach minimizes potential bias in responses by providing a nonevaluative context to them, such that interviewees were less inclined to feel the need to justify or rationalize their actions as participants in the experiment. Notwithstanding these advantages, we were also cognizant of the potential for the presence of social desirability in guests' responses related to how they intended to act, as opposed to their actual behavior. Following previous research, to minimize social desirability bias in data collection, we assured confidentiality to participants and also used photo-elicitation techniques in situ (King \& Horrocks, 2010; Meyer, Hollerer, Jancsary \& Van Leeuwen, 2013). With the potential for social desirability bias in mind, we thought that the guests might express greater concern for the environment and care towards others than they might actually have. Therefore, we framed our interview questions to avoid any responses related to the environment and housekeeping staff, and asked all questions in a nonevaluative manner. Further, we approached our analysis carefully and systematically (as elaborated in the next section), including with regards to detecting social desirability. Although we cannot completely rule it out, the wide range of responses given by interviewees helped us feel confident that our findings were not influenced by social desirability bias.

Data analysis. In analyzing the interview data, we followed a bottom-up approach allowing the theoretical concepts to emerge from the data (Glaser \& Strauss, 1967), and drew 
upon display techniques for data analysis (Miles \& Huberman, 1994). We conducted first-order analysis to capture understandings in the terms of our informants, and second-order analysis to develop the more abstract, theoretical concepts and dimensions (Gioia, Corley \& Hamilton, 2012).

Our data analysis included four major steps. First, we read through the interview transcripts, taking extensive notes, and creating a summary of each interview. The interview participants predominantly described their behaviors in terms of artifacts, likely because the routine redesign mainly involved changes to artifacts (e.g., locations for depositing towels as supporting artifacts). This might also have been because, unlike other interface routines such as in fast-food restaurants (Leidner, 1993), the towel-changing routine was almost entirely devoid of verbal interaction between organizational members and external parties. Second, we partitioned the interview transcripts into relevant segments of text, such as "If there is a sign, then I would use the hamper for replacing the towels. I follow instructions." In partitioning the transcripts into meaningful text segments, we focused on informant descriptions of how artifacts in the control and treatment groups would influence their actions in the routine. Third, we engaged in a process of open-coding these descriptions, which included frequently revisiting the interview text while developing the codes. For example, a first-order code for the text segments related to sign usage was "Use of representational artifacts to understand what actions the hotel wants for towel replacement/reuse." To increase reliability, two researchers independently coded the data, and any differences in the codes were resolved through discussion and further iterations with the data. We then compared and contrasted informant descriptions for the elements of both routines to discern major themes. Fourth, we extracted the theoretical observations and aggregate theoretical dimensions from the first-order findings, which included working back and forth between the interview transcripts and interview summaries, and periodically relating the 
emerging themes to extant research in the routines literature. Through this iterative process, we identified six processes and grouped them into three theoretically meaningful categories, which together can explain how understanding-based redesign helps routine participants to understand the actions expected of them, the outcomes of their actions, and the implications of their actions for interactions in the routine. Next, we present together the first- and second-order findings (Eisenhardt \& Graebner, 2007) in Table 2 and elaborate below.

Please insert Table 2 about here

\section{Understanding of Expected Actions: Interpreting and Relating}

Interpreting. In a number of interviews, guests explained that the sign on the bathroom counter helped them to interpret how hotel management intends for them to act in the routine. This aligns with the idea that participants in routines use artifacts like standard operating procedures to figure out "what actions should occur" (Cohen in Cohen et al., 1996: 673). As one informant explained, "usually [the sign] tells you what they want, so that you know -- because usually you want your towels to be cleaned, so you check to make sure how they're gonna get exchanged". Another remarked "well, I would read the sign and probably do what they told me to do." Interestingly, some guests indicated that they base their interpretations on the mere presence of the sign, even if they do not pay close attention to its content. For example, one guest indicated: "If I started reading this, I probably wouldn't finish reading it. I would probably say -okay, I know that message, I've read it 100 times".

Relating. Hotel guests emphasized how they understand the actions expected of them by reflecting on the ways in which they have utilized similar artifacts to perform similar activities in their homes. One informant commented on using the hook: "this is exactly what I have at home, so I'm used to that". A guest described his view of the wicker basket along similar lines: "It is a 
laundry basket. It's convenience. It's the sort of thing I have at home for putting my laundry in when it's waiting to be washed. It's clear what it is for. No ambiguity". This is consistent with the idea that established schemas shape behavior (Fiske \& Taylor, 1984), and specifically that the images and artifacts individuals encounter invoke their knowledge and experience to facilitate action (Crossan, Lane \& White, 1999).

Together, the above observations and findings suggest that understanding-based redesign facilitates participants' actions through (a) an interpreting process in which participants use representational artifacts to understand what actions are expected of them, and (b) a relating process in which participants use a particular artifact based on how they have previously used similar artifacts to perform similar actions in other settings. Together, the interpreting and relating processes leverage understanding of expected actions by participants, i.e., actions expected to be performed by them to meet the objectives of the routine.

\section{Understanding of Action Outcomes: Functioning and Rendering of Artifacts}

Functioning. Guests at PSH explained how they would perform actions using certain artifacts, and not others, based on how well they felt the artifact would function in helping them to accomplish their objective pertaining to towel reuse or replacement. For example, one guest indicated: "I would prefer the hook because the towel dries better. You don't have to fold the towel". Another explained why she would not use the towel rack: "If I fold it up and put it back on the towel rack, it won't dry, it would be smelly". This is similar to the idea of instrumentality of an artifact, i.e., the extent to which it contributes to performing a related task or accomplishing desired goals (Rafaeli \& Vilnai-Yavetz, 2004). However, the process of functioning contextualizes the instrumentality from the view of particular participants and their experiences, rather than from the view of the overall routine. From the perspective of the routine, leaving the towel on a rack communicates to the housekeeping staff that the towel need not be changed. But 
from the view of guests, leaving towels on a rack would make them less suitable for reuse because of dampness and smell. As a result, the door hook seems to be functioning better for the guests than the towel rack to meet their objectives.

Rendering. Guests at PSH also described how their actions would be based on the appearances rendered from the result of their actions, similar to the notion of aesthetics, which reflects the sensory reactions elicited by an artifact (Rafaeli \& Vilnai-Yavetz, 2004). ${ }^{6}$ But rather than the sensory reactions stimulated by an encountered artifact alone, as suggested by Rafaeli \& Vilnai-Yavtez (2004), our informants took into account the aesthetic outcomes generated by the combination of artifacts resulting from their actions. For example, one guest explained that it is "classier" to keep used towels in the wicker basket, while another said: "it looks more professional, it looks nicer". Similarly, guests also reported that they would not use certain artifacts because it would render an unattractive appearance. As one guest indicated, "It kind of goes against my sense of cleanliness in that I don't like to leave things messy... It would be better if you could throw the towel in another place, rather than a bathtub".

Taken together, these accounts suggest that understanding-based redesign influences participant actions through (a) a functioning process in which participants act based on the functional consequences of using a particular artifact to accomplish a desired outcome, and (b) a rendering process in which participants take into account the appearances that will be rendered by a combination of artifacts. Together, the functioning and rendering processes leverage understanding of participants related to action outcomes, i.e., suitability of artifactual dimensions to accomplish a desired and pleasant outcome for participants.

\section{Understanding of the Implications for Interactions: Communicating and Facilitating}

Communicating. In a number of interviews, guests described that they would perform certain actions because those actions would clearly communicate to the housekeepers the 
intentions of guests related to towel reuse/replacement. As one guest remarked, by leaving towels in the bathtub, "then the staff know. There's no confusion that if it is there, in a certain spot, then that means they want to switch them over". Another remarked that he would leave them on the floor because "it sends a pretty clear message that those need to be replaced, but if you put them on the rack, it doesn't." One guest described that he would alter the spatial arrangement to more clearly communicate his intention to housekeepers: "I might move the basket to the bathtub, so that it was very clear... probably move it to like the center of the room, so it was very clear that my dirty towels were in the basket". These efforts by guests to communicate with housekeepers are consistent with the idea that participants interpret and respond to actions against a backdrop of shared meaning (Crossan et al., 1999), and with previous findings that suggest that intermediaries (like towels) communicate the intentions of one actor to another thus helping to enable the emergence of a routine (Bapuji et al., 2012).

Facilitating. In addition to considering what their actions would communicate to the housekeeping staff, guests also reported that they would consider how their actions would facilitate the job of housekeeping staff. One guest explained that she would not leave towels for replacement in the bathtub "because the cleaner has to bend over and pick it up, which is an extra effort for him or her." Another expressed a similar view, saying "I don't personally put my towels in the bathtub... It just feels like, oh, there's a nice basket here. I'll just put my towels in here. And as someone who does laundry, too, it's just easier to grab the basket as a housekeeping staff." These findings are in line with prior research that shows individuals who pay attention to the needs of others and their roles tend to make efforts to act in ways that facilitate others' performance, such as by sharing customized knowledge (Uzzi \& Lancaster, 2003).

Taken together, these accounts suggest that understanding-based redesign facilitates interactions among participants through (a) a communicating process where participants convey 
their own intentions as to what actions are desired of other participants, and (b) a facilitating process in which participants act to facilitate the actions of other participants. Together, the communicating and facilitating processes leverage understanding of participants related to implications of their actions to other participants, i.e., the suitability of participant actions to support interdependent actions by other participants.

In sum, our analysis of the interview data suggests six processes through which understanding-based redesign facilitates participant actions and interactions in a routine. Given the nature of the routine we have studied and our redesign, the six processes above are expressed as they relate to the use of artifacts. However, these processes can be more generally applicable to actions in routines, and their effectiveness. In the next section, we draw on our study findings to propose a model that explains how understanding-based redesign influences the actions of routine participants that support routine effectiveness.

\section{Summary of interview findings and model}

As presented in Figure 2, we propose three core ways in which understanding-based redesign works through participant actions to enhance routine effectiveness by facilitating greater alignment between the actions taken by routine participants and those expected of them by other participants. The first way relates to participants' understandings of what actions they are to perform in the routine. The processes of interpreting and relating help participants to make sense of what is expected of them; specifically, participants make use of representational artifacts and their own prior experiences to understand the actions expected of them. Thus, we propose that participants are more likely to act in ways expected of them in the routine when those ways align with their understandings of the actions.

Please insert Figure 2 about here 
The second way relates to participants' understandings of the outcomes generated by their actions. Our findings indicate that functioning and rendering of artifacts influence participants' actions based on outcome favorability. From this, we suggest that participants are more likely to readily act in the ways expected of them in the routine if the dimensions of artifacts in the redesigned routine support action outcomes that are viewed as favorable by participants. The third way relates to how participants understand the implications of their actions for interactions in the routine. Our interview accounts show how participants use artifacts as a means of communicating what actions are desired of other participants in the routine, and facilitating the interdependent actions of other participants. Thus, we propose that participants are more likely to perform their roles in expected ways, when those ways align with their understandings of interdependence dimensions, such as effective communication with other participants, and facilitation of their actions.

Our initial theorization suggested that understanding-based redesign enhances routine effectiveness because it aligns more closely with participants' related schemas, i.e., their understandings regarding how to perform the actions expected of them. The model above suggests that participant understandings about their roles are not only about what actions they perceive as expected of them, but also relate to how best to carry out the expected actions using artifacts, and the implications of their actions for interactions with other routine participants.

In sum, we propose that understanding-based redesign enhances routine effectiveness through participants' actions by leveraging understandings in three core ways -- actions expected of them, outcomes generated by their actions, and interactions facilitated by their actions.

\section{DISCUSSION}

In this study, we set out to examine how understanding-based redesign influences routine 
effectiveness. We argued that understanding-based redesign would improve the effectiveness of a routine by leveraging participants' related schemas, such that they will have greater familiarity with their roles in the routine and will be able to form more reliable expectations of other participants. Through a field experiment, we found that understanding-based redesign resulted in corresponding changes in the actions of routine participants, and in greater effectiveness of the routine. Moreover, the results pointed to an important uncertainty-reducing effect underlying the redesign-effectiveness results; specifically, the redesign enhanced the interactions between guests and housekeepers over time, as it resulted in guests leaving fewer towels in nondesignated (i.e., ambiguous) locations. To enrich our understanding of the effects of understanding-based redesign, we conducted semi-structured interviews with hotel guests. Based on our analysis of the interviews, we propose six processes (i.e., relating, interpreting, functioning, rendering, communicating, and facilitating) through which understanding-based redesign leverages participant understandings in three core ways -- actions expected of them, outcomes generated by their actions, and interactions facilitated by their actions -- which in turn support greater routine effectiveness. Based on these findings and insights, we offer several important implications for strategy and organizations research focusing on routines, as well as for management practice.

First, while researchers have emphasized how firms create value through the transfer and replication of superior routines (Argote \& Ingram, 2000; Winter \& Szulanski, 2001), there has been less optimism surrounding the redesign of routines. Routines scholars working from the perspective of memory and coordination have argued, and often found, that change in the formal structure and elements of a routine disrupts the learned pattern of interactions and can be detrimental to organizations (Baum \& Shipilov, 2006; Cohen \& Bacdayan, 1994). By contrast, our study argues that understanding-based redesign can improve routine effectiveness by 
facilitating participants' actions, and thus enhancing the pattern of interactions constituting the routine, and we find empirical support for this core idea.

By developing the concept of understanding-based redesign and showing how it improves routine effectiveness, our study responds to calls for greater scholarly attention to routine redesign and its consequences (e.g., Gupta et al., 2015). In prior research, scholars have shown that beneficial effects can arise from changes in routine design (Bapuji et al., 2012; Darr et al., 1995; Edmondson et al., 2001). Building on that work, we find that incremental changes in routine design can result in considerable improvement in its effectiveness when those changes leverage the existing understandings of routine participants and reduce the uncertainty pertaining to their interactions. These existing understandings are often based in prior experiences, and involve a blend of tacit and explicit knowledge (Nonaka, 1994) which individuals draw upon as they consider actions, assess outcomes, and anticipate other participants' responses. This speaks to a recent call for microfoundations-based research to further our understanding of individuals' action propensities within artifactual and organizational contexts, given that such understanding may have implications for how "small nudge" interventions can generate large-scale improvements for organizations (Felin, Foss \& Ployhart, 2015).

Moreover, our empirical focus on a simple interface routine performed by a small number of individuals has enabled us to direct further attention to the limited base of scholarly work on routines involving few connections and largely indirect interactions among participants (Howard-Grenville \& Rerup, 2017). This limited attention likely reflects historical emphasis in the literature on routines as a feature of organizations (Nelson \& Winter, 1982; Stene, 1940), and by natural extension consideration of intraorganizational routines, i.e., those routines that exist within organizational boundaries and typically involve frequent interactions among employees. Yet with the continued expansion of the knowledge economy and its derivatives like the sharing 
economy, many organizations are becoming increasingly dependent on information flows and operations that span boundaries. Consequently, we believe that our research has particular salience in the current business environment, as interface routines become more prevalent and routines researchers continue to turn their attention towards them (e.g., Bapuji et al., 2012; Holloway \& Parmigiani, 2016; Turner \& Rindova, 2012).

A second contribution of the study lies in extending understanding of how design and artifacts shape the patterns of actions and interactions constituting routines (D'Adderio, 2011; Parmigiani \& Howard-Grenville, 2011), particularly for those routines that have limited connections among participants (Howard-Grenville \& Rerup, 2017). In their review of the routines literature, Parmigiani and Howard-Grenville (2011: 439) highlight that "artifacts appear to have an important, but somewhat ambiguous role in routines. Sometimes they matter a great deal; at other times, they only minimally encode a routine and do even less to influence its ongoing use." Our process model advances scholarly knowledge of artifacts' influence by revealing three core ways in which they work through understandings to shape the actions and interactions that constitute the routine. The first way focuses on how artifacts influence participants' actions through their understandings of what is expected of them in the routine; this occurs through interpreting (via representational artifacts), and by relating (through prior experiences) processes. The second way relates to participants' understandings of the outcomes generated by their actions, which depend on the functioning and rendering of employed artifacts. The third way relates to participants' understanding of the implications of their actions for interactions within the routine; specifically, our findings emphasize how participants use artifacts to communicate their intentions to, and facilitate the actions of, other participants. Our findings accentuate the multi-dimensional influences that artifacts can have on actions, and offer greater clarity regarding the role of artifacts in routines. 
We note that a number of the findings and insights that emerged from our interviews relate to research on social and situated cognition that center on schemas (Elsbach, Barr \& Hargadon, 2005; Fiske \& Taylor, 1984), and the literature on organizational learning (Bapuji \& Crossan, 2004; Crossan et al., 1999; Levitt \& March, 1988). For example, the relating process is consistent with the idea that people's actions are influenced by interactions between object schemas, i.e., knowledge structures about objects and how they work, and the context (Elsbach, et al., 2005); and that the images and artifacts individuals encounter invoke their knowledge and experience to facilitate action (Crossan et al., 1999). Similarly, the communicating process is consistent with the idea that people take actions based on how they perceive the actions to be interpreted by other parties, which is influenced by the role schemas that people hold for the other parties; these role schemas are structures that organize knowledge about the norms and behaviors of people in particular social positions (Fiske \& Taylor, 1984). In addition to supporting our core ideas, schema-based research may present an opportunity for future research to delve further and gain additional insight into the multiple mechanisms by which the design and redesign of routines can work through artifacts to guide participant actions in productive ways. And from the view of organizational learning, while scholars recognize that organizational learning is institutionalized in routines (Crossan et al., 1999; Levitt \& March, 1988), less attention has been directed to the mechanisms through which such learning is institutionalized in routines; our findings and insights offer a promising direction for future research to explore how organizations can institutionalize learning by designing suitable artifacts into routines.

This model also has implications for advancing scholarly understanding of the tensions within routines (D'Adderio, 2011; Pentland \& Feldman, 2005), and helping organizations in their efforts to address them. While routines scholars have emphasized that formal procedures and rules play an important role in the performance of routines (Parmigiani \& Howard-Grenville, 
2011), there is also recognition that considerable divergence often exists between the routine as represented or espoused in artifacts (e.g., formal procedure) and the routine as actually performed (Cohen et al., 1996; Pentland \& Feldman, 2008; Rerup \& Feldman, 2011). In extant research, scholars have argued that the incentives/disincentives put in place by management (e.g., financial incentives) have a strong influence on the extent of convergence between the routine as represented/espoused and the routine as performed (D'Adderio, 2011; Lazaric \& Denis, 2005), emphasizing the ways that management can more directly influence the actions of employees in routines. By contrast, our study offers insight into how routine participants whose actions are less subject to hierarchical control, such as customers, can be motivated to act in ways that are consistent with the procedure/rules. In particular, our model suggests three core ways in which participants' understandings -- those related to expected actions, experienced outcomes, and implications for interdependent actions -- influence how they perform their roles. A third contribution from our study is the use of a novel, mixed methods research strategy to examine how the redesign of a routine influences its effectiveness. Previous empirical research examining the design and redesign of routines has tended to employ one of two methodologies: archival records and case studies. For example, strategy scholars examining the performance consequences of exact replication versus local adaptation have used archival data (Winter et al., 2012) and longitudinal case studies (Jensen \& Szulanski, 2007) for theory testing. Other studies examining the process of redesign have emphasized longitudinal case studies (Bresman, 2013; Gupta et al., 2015) for purposes of theory development, as has work examining how routines are changed through artifacts (Parmigiani \& Howard-Grenville, 2011). However, scholars have also recognized the limitations associated with particular methodologies (McGrath, 1995), and have advocated the use of a diverse array of methods, particularly as research areas develop and mature (Becker et al., 2005; Chatterji et al., 2016). Recently, routines scholars have 
called for more integrative approaches to organizational research (Salvato \& Rerup, 2011) as they have strong potential to generate actionable insights for managers (Aguinis et al., 2011).

Our study offers several managerial implications for firms in the hotel industry, as well as for large chain organizations more generally. Even though more than $75 \%$ of U.S. hotels have a towel reuse program, guests often fail to participate in them, as many would like to treat themselves to fresh towels every day (Hetter, 2013). Our study shows that understanding-based redesign using more appropriate artifacts can be used in hotels to help influence guests' towel reuse behavior, and thus achieve considerable reduction in towel usage. The insights from our study may prove particularly salient for interface routines in large chain organizations, whose success largely depends on their ability to replicate routinized behavior across their organizational units. Simple replication of an interface routine does not, however, ensure effectiveness as evidenced by the towel-changing routine. In many cases, success depends a great deal on customers who are outsiders following particular rules of engagement with the organization. However, customers themselves might not necessarily follow the rules, or even ignore them, because of competing institutional logics (Thornton, Ocasio \& Lounsbury, 2012). For example, in our empirical setting, the logic of "I'm paying for a room so I want fresh towels everyday" may exist in opposition to "I should help to save the environment and reuse my towel" in a towel-changing routine. ${ }^{7}$ Even though competing institutional logics may co-exist, employees and customers can be influenced to move from one logic to another (Reay \& Hinings, 2009). Our study shows how the artful use of familiar artifacts in routines can influence macro institutional logics and yield performance benefits, particularly for large chain organizations.

More broadly, our study also has managerial implications for firms operating in the knowledge economy whose work spans organizational boundaries through interface routines. In many organizations, there is increasing dependence on an open innovation process in which 
knowledge purposively flows back and forth across organizational boundaries to help accelerate internal innovation and also expand markets for the external use of innovation (Chesbrough, West \& Vanhaverbeke, 2006). For example, Toyota along with its suppliers have enjoyed great success by leveraging knowledge sharing networks consisting of institutionalized routines that facilitate multidirectional knowledge flows and afford productivity advantages (Dyer \& Nobeoka, 2000). In addition, with the more prevalent spread of routines in which customers are active participants, as in the sharing economy (e.g., Uber customers using smartphones to order and pay for a ride) or in the retail sector (e.g., self-service checkout), we expect to see more organizations employing interface routines, with managers increasingly interested in ways that they can effectively design and enhance them. Our findings suggest that leveraging artifacts through understanding-based redesign is an important avenue for making such routines more effective.

The findings of our study must also be interpreted within the context of its limitations. First, it is possible that the housekeeping staff might have been more diligent in performing the routine because we asked them to additionally record the number of towels left at various locations and the number of towels changed. Although this concern is partially alleviated because any enhanced attentiveness would have been consistent across the treatment and control groups, we cannot rule out that such attentiveness has influenced our findings. Second, we ran the experiment over a four-week period, which was enough to collect the data we needed for empirical testing, but not enough to reliably draw inferences about long-term effectiveness of routine redesign. Third, the towel-changing routine is performed by staff members at the boundary of the organization and by customers who participate in the routine infrequently. As a result, our findings might not be readily generalizable to other organizational routines performed by organizational members over extended periods of time. Finally, we conducted our experiment 
in an industry and country where towel-changing and linen-changing procedures are very common. Therefore, the generalizability of our findings to other industry and country contexts cannot be readily inferred.

In conclusion, despite its vibrancy, routines research is still "a long way from having an authoritative textbook for students in professional training who want to know how to create effective organizational routines, or how to modify them when they could be still better" (Cohen, 2007: 774). We suggest that routine effectiveness can be enhanced by leveraging the understandings of routine participants related to expected actions, experienced outcomes, and consequences for interdependent action. By keenly studying interface routines that span the boundaries of an organization, scholars can generate greater insights into how routine redesign influences actions and interactions in a routine, and thus enhances their effectiveness. We hope that the present study makes a small contribution towards this important pursuit. 


\section{FOOTNOTES}

${ }^{1}$ Scholars have explained that this design-performance divergence is not necessarily a problem for the coordination of interactions, as long as the divergence from the design is consistent with the empirically-based expectations of routine participants (Nelson \& Winter, 1982). However, given the bounded rationality of participants (March \& Simon, 1958), what constitutes a regular pattern of divergence for one participant may not be easy for another participant to know, thus resulting in coordination problems.

${ }^{2}$ Consistent with Nelson and Winter (1982: 96-97), from the view of scope, we highlight that our argument applies for organizational activities that are largely "the same" over time, such as providing a particular type of service for customers. By contrast, our argument may be less likely to hold for those activities that are principally directed to the generation of innovation and change (e.g., activities for developing novel products).

${ }^{3}$ As counter examples that are consistent with our argument, we highlight two empirical studies in which routine redesign either failed to take hold (Feldman, 2003) or had detrimental implications (Cohen \& Bacdayan, 1994), largely because the change in design ran counter to understandings that participants had developed regarding how the routine works (Cohen \& Bacdayan, 1994) or how the organization in which the routine is embedded operates (Feldman, 2003). These two studies are broadly consistent with the idea that to take hold, the redesigned routine needs to be viewed as legitimate by participants.

${ }^{4}$ Although housekeepers' actions are divergent and thus affect routine effectiveness, we reasoned that this divergence arose mainly because guest actions were not clear to housekeeping staff. If guest actions reliably inform housekeepers their intent with respect to towels, divergence in housekeepers' actions will likely be reduced. In other words, although the divergence is manifested in housekeeping staff actions, it likely originated from guest actions. Therefore, we focused on influencing guest actions in our field experiment.

${ }^{5}$ Bapuji et al. (2012) draw from these data to examine the emergence of routines from interactions enabled by the exchange of intermediaries. The contribution of the present study lies in establishing how understanding-based redesign increases routine effectiveness through an uncertainty-reducing mechanism over time, and further by inductively developing theory as to the processes by which understanding-based redesign influences participant actions that support routine effectiveness.

${ }^{6}$ Rafaeli and Vilnai-Yavetz (2004) expound on three dimensions of artifacts: instrumentality, aesthetics, and symbolism. Our analysis revealed a functioning process based on instrumentality, and a rendering process based on aesthetics. However, the symbolic dimension of artifacts appears to underpin the rendering process to some extent; the wicker basket seems to render associations with values like 'classiness', 'professionalism' and 'cleanliness'. ${ }^{7}$ We thank an anonymous reviewer for this point. 


\section{REFERENCES}

Aguinis, H., Boyd, B.K., Pierce, C.A., \& Short, J.C. 2011. Walking new avenues in management research methods and theories: Bridging micro and macro domains. Journal of Management, 37: 395-403.

American Hotel \& Lodging Association. 2016. http://www.ahla.com/Green.aspx?id=35741. Accessed August 24, 2016.

Argote, L. 1982. Input uncertainty and organizational coordination in hospital emergency units. Administrative Science Quarterly, 27: 420-434.

Argote, L. 2013. Organizational learning: Creating, retaining and transferring knowledge (2nd ed.). New York: Springer.

Argote, L., \& Ingram, P. 2000. Knowledge transfer: A basis for competitive advantage in firms. Organizational Behavior and Human Decision Processes, 82: 150-169.

Banbury, C.M., \& Mitchell, W. 1995. The effect of introducing important incremental innovations on market share and business survival. Strategic Management Journal, 16: 161-182.

Bapuji, H., Hora, M., \& Saeed, A. 2012. Intentions, intermediaries, and interaction: Examining the emergence of routines. Journal of Management Studies, 49(8):1586-1607.

Bapuji, H., \& Crossan, M. 2004. From questions to answers: Reviewing organizational learning research. Management Learning, 35(4):397-417.

Baum, J.A., \& Shipliov, A.V. 2006. Ecological approaches to organizations. In S. Clegg, C. Hardy, T. Lawrence, \& W. Nord (Eds.), Sage Handbook of Organizational Studies (2nd ed.): 55-110. London: Sage

Becker, M.C. 2004. Organizational routines: A review of the literature. Industrial and Corporate Change, 13(4): 643-677.

Becker, M.C. 2005. The concept of routines: Some clarifications. Cambridge Journal of Economics, 29: 249-262.

Becker, M.C., Lazaric, N., Nelson, R.R., Winter, S.G. 2005. Applying organizational routines in understanding organizational change. Industrial and Corporate Change, 14(5): 775-791.

Bresman, H. 2013. Changing routines: A process model of vicarious group learning in pharmaceutical R\&D. Academy of Management Journal, 56(1): 35-61.

Cacciatori, E. 2012. Resolving conflict in problem-solving: Systems of artefacts in the development of new routines. Journal of Management Studies, 49(8): 1559-1585.

Camerer, C., \& Knez, M. 1996. Coordination, organizational boundaries and fads in business practices. Industrial and Corporate Change, 5: 89-112.

Carbon, C., \& Leder, H. 2005. The repeated evaluation technique (RET). A method to capture dynamic effects of innovativeness and attractiveness. Applied Cognitive Psychology, 19: 587-601.

Chatterji, A.K., Findley, M., Jensen, N.M., Meier, S., \& Nielsen, D. 2016. Field experiments in strategy. Strategic Management Journal, 37(1): 116-132.

Chesbrough, H.W., West, J., \& Vanhaverbeke, W. 2006. Open innovation: Researching a new paradigm. Oxford University Press: Oxford.

Cohen, M.D. 2007. Reading Dewey: Reflections on the study of routine. Organization Studies, 28(5): 773-786.

Cohen, M.D., \& Bacdayan, P. 1994. Organizational routines are stored as procedural memory: Evidence from a laboratory study. Organization Science, 5(4): 554-568.

Cohen, M.D., Burkhart, R., Dosi, G., Egidi, M., Marengo, L., Warglien, M., \& Winter, S. 1996. Routines and other recurring action patterns of organizations: Contemporary research issues. Industrial and Corporate Change, 5(3): 653-698. 
Creswell, J.W. 2014. Research design: Qualitative, quantitative, and mixed methods approaches. Thousand Oaks: Sage.

Crossan, M., Lane, H., \& White, R. 1999. An organizational learning framework: From intuition to institution. Academy of Management Review, 24(3): 522-537.

Cyert, R.M., \& March, J.G. 1963. A Behavioral Theory of the Firm. Englewood Cliffs: PrenticeHall.

Danner-Schröder, A., \& Geiger, D. 2016. Unravelling the motor of patterning work: Toward an understanding of the microlevel dynamics of standardization and flexibility. Organization Science, 27: 633-658.

D’Adderio, L. 2011. Artifacts at the centre of routines: Performing the material turn in routines theory. Journal of Institutional Economics, 7(2): 197-230.

Darr, E.D., Argote, L., \& Epple, D. 1995. The acquisition, transfer, and depreciation of knowledge in service organizations: Productivity in franchises. Management Science, 41(11): 1750-1762.

Dewar, R.D., \& Dutton, J.E. 1986. The adoption of radical and incremental innovations: An empirical analysis. Management Science, 32(11): 1422-1433.

Dionysiou, D.D., \& Tsoukas, H. 2013. Understanding the (re)creation of routines from within: A symbolic interactionalist perspective. Academy of Management Review, 38: 181-205.

Dittrich, K., Guerard, S., \& Seidl, D. 2016. Talking about routines: The role of reflective talk in routine change. Organization Science, 27(3): 678-697.

Dyer, J.H., \& Nobeoka, K. 2000. Creating and managing a high-performance knowledge-sharing network: The Toyota case. Strategic Management Journal, 21(3): 345-367.

Edmondson, A.C., Bohmer, R.M., \& Pisano, G.P. 2001. Disrupted routines: Team learning and new technology implementation in hospitals. Administrative Science Quarterly, 46: 685716.

Eisenhardt, K.M. 1989. Building theory from case research. Academy Management Review, 14(4): 532-50.

Eisenhardt, K.M., \& Graebner, M.E. 2007. Theory building from cases: Opportunities and challenges. Academy Management Journal, 50(1): 25-32.

Elsbach, K.D., Barr, P.S., \& Hargadon, A.B. 2005. Identifying situated cognition in organizations. Organization Science, 16: 422-433.

Feldman, M.S. 2003. A performative perspective on stability and change in organizational routines. Industrial and Corporate Change, 12(4): 727-752.

Feldman, M.S., \& Pentland, B. 2003. Reconceptualizing organizational routines as a source of flexibility and change. Administrative Science Quarterly, 48: 94-118.

Feldman, M.S., Pentland, B.T., D'Adderio, L., \& Lazaric, N. 2016. Beyond routines as things: Introduction of the special issue on routine dynamics. Organization Science, 27: 505-513.

Feldman, M.S., \& Rafaeli, A. 2002. Organizational routines as sources of connections and understandings. Journal of Management Studies, 39(3): 309-331.

Felin, T., Foss, N.J., Heimeriks, K.H., \& Madsen, T.L. 2012. Microfoundations of routines and capabilities: Individuals, processes, and structure. Journal of Management Studies, 49(8): 1351-1374.

Felin, T., Foss, N.J., \& Ployhart, R.E. 2015. The microfoundations movement in strategy and organization theory. Academy of Management Annals, 9(1): 575-632.

Fiske, S.T., \& Taylor, S.E. 1984. Social cognition. Reading, MA: Addison-Wesley.

Gavetti, G., \& Levinthal, D. 2000. Looking forward and looking backward: Cognitive and experiential search. Administrative Science Quarterly, 45: 113-137. 
Gavetti, G., \& Levinthal, D.A. 2004. The strategy field from the perspective of Management Science: Divergent strands and possible integration. Management Science, 50(10): 13091318.

Gioia, D.A., Corley, K.G., \& Hamilton, A.L. 2012. Seeking qualitative rigor in inductive research: Notes on the Gioia methodology. Organizational Research Methods, 16: 15-31.

Glaser, B.G., \& Strauss, A.L. 1967. The discovery of Grounded Theory: Strategies for qualitative research. New York: Aldine de Gruyter.

Goldstein, N., Cialdini, R., \& Griskevicius, V. 2008. A room with a viewpoint: Using social norms to motivate environmental conservation in hotels. Journal of Consumer Research, 35: 472-482.

Grant, R.M. 1996. Toward a knowledge-based theory of the firm. Strategic Management Journal, 17: 109-122.

Greenberg, J., \& Tomlinson, E.C. 2004. Situated experiments in organizations: Transplanting the lab to the field. Journal of Management, 30(5): 703-724.

Gupta, A., Hoopes, D.G., \& Knott, A.M. 2015. Redesigning routines for replication. Strategic Management Journal, 36(6): 851-871.

Hamilton, B.H., \& Nickerson, J.A. 2003. Correcting for endogeneity in strategic management research. Strategic Organization, 1: 51-78.

Harper, D. 2002. Talking about pictures: A case for photo elicitation. Visual Studies, 17: 13-26.

Harrison, G.W., \& List, J.A. 2004. Field Experiments. Journal of Economic Literature, 42(4): 1009-1055.

Helfat, C.E. 2003. Stylized facts regarding the evolution of organizational resources and capabilities. In C.E. Helfat (Ed.), The SMS Blackwell Handbook of Organizational Capabilities: 1-11. Malden, MA: Blackwell.

Helfat, C.E., \& Karim, S. 2014. Fit between organization design and organizational routines. Journal of Organization Design, 3(2): 18-29.

Helfat, C.E., \& Peteraf, M.A. 2003. The dynamic resource-based view: Capability lifecycles. Strategic Management Journal, 24: 997-1010.

Hetter, K. 2013. Hotel Towel Dilemma: Replace or Reuse? Retrieved from http://www.cnn.com/2013/03/06/travel/sustainable-hotels/index.html [Accessed 6 March 2013].

Holloway, S.S. \& Parmigiani, A. 2016. Friends and profits don't mix: The performance implications of repeated partnerships. Academy of Management Journal, 59(2): 460-478

Howard-Grenville, J.A. 2005. The persistence of flexible organizational routines: The role of agency and organizational context. Organization Science, 16: 618-636.

Howard-Grenville, J., \& Rerup, C. 2017. A process perspective on organizational routines. In Langley, A., \& Tsoukas, H. (Eds.), SAGE Handbook of Process Organization Studies: 323-339. London: SAGE Publications.

Jensen, R.J., \& Szulanski, G. 2007. Template use and the effectiveness of knowledge transfer. Management Science, 53(11): 1716-1730.

Joshi, C., Bapuji, H., \& Chandrasekhar, R. 2013. Windermere Manor: Sustainability and Change. Ivey Publishing (Case No. 9B13C044), London: Canada.

Karim, S., \& Mitchell, W. 2000. Path-dependent and path-breaking change: Reconfiguring business resources following acquisitions in the U.S. medical sector, 1978-1995. Strategic Management Journal, 21: 1061-1081.

King, N., \& Horrocks, C. 2010. Interviews in Qualitative Research. London: Sage.

Lazaric, N., \& Denis, B. 2005. Routinization and memorization of tasks in a workshop: The case of the introduction of ISO norms. Industrial and Corporate Change, 14(5): 873-896. 
Lee, T.W., Mitchell, T.R., \& Sablynski, C.J. 1999. Qualitative research in organizational and vocational psychology, 1979-1999. Journal of Vocational Behavior, 55: 161-187.

Leidner, R. 1993. Fast food, fast talk: Service work and the routinization of everyday life. Berkeley: University of California Press.

Leonardi, P.M., \& Barley, S.R. 2010. What's under construction here? Social action, materiality, and power in constructivist studies of technology and organizing. Academy of Management Annals, 4: 1-51.

Levitt, B., \& March, J.G. 1988. Organizational learning. Annual Review of Sociology, 14: 13191340.

Lippman, S.A., \& Rumelt, R.P. 1982. Uncertain imitability: An analysis of interfirm differences in efficiency under competition. Bell Journal of Economics, 13(2): 418-438.

March, J. 1991. Exploration and exploitation in organizational learning. Organization Science, 2(1):71-87.

March, J., \& Simon, H. 1958. Organizations. New York: John Wiley \& Sons.

Maritan, C.A., \& Brush, T.H. 2003. Heterogeneity and transferring practices: Implementing flow manufacturing in multiple plants. Strategic Management Journal, 24: 945-959.

Martin, J.A., \& Helfat, C.E. 2015. Dynamic managerial capabilities: Review and assessment of managerial impact on strategic change. Journal of Management, 41: 1281-1312.

McGahan, A.M., \& Mitchell, W. 2007. How do firms change in the face of constraints to change? Toward an agenda for research on strategic organization. Strategic Organization, 1(2): 231-239.

McGrath, J.E. 1995. Methodology matters: Doing research in the behavioral and social sciences. In R.M. Baecker (Ed.), Readings in human-computer interaction: Toward the year 2000: 152-169. Morgan Kaufman.

Meyer, R. E., Höllerer, M. A., Jancsary, D., \& Van Leeuwen, T. 2013. The visual dimension in organizing, organization, and organization research: Core ideas, current developments, and promising avenues. The Academy of Management Annals, 7(1): 489-555.

Miles, M.B., \& Huberman, A.M. 1994. Qualitative Data Analysis: An Expanded Sourcebook. London: Sage.

Miller, K.D., Pentland, B.T., \& Choi, S. 2012. Dynamics of performing and remembering organizational routines. Journal of Management Studies, 49(8): 1536-1558.

Nelson, R.R. 1994. Routines. In G.M. Hodgson, W.J. Samuels, \& M.R. Tool (Eds.), Elgar Companion to Institutional and Evolutionary Economics, Vol. 2, 249-253. Brookfield, VT: E. Elgar.

Nelson, R.R., \& Nelson, K. 2002. Technology, institutions, and innovation systems. Research Policy, 31: 265-272.

Nelson, R.R., \& Sampat, B.N. 2001. Making sense of institutions as a factor shaping economic performance. Journal of Economic Behavior \& Organization, 44: 31-54.

Nelson, R., \& Winter, S. 1982. The Evolutionary Theory of the Firm. Cambridge: The Belknap Press of Harvard University Press.

Nicolini, D., Mengis, J., \& Swan, J. 2012. Understanding the role of objects in cross-disciplinary collaboration. Organization Science, 23(1): 612-629.

Nonaka, I. 1994. A Dynamic Theory of Organizational Knowledge Creation, Organization Science, 5(1): 14-37

Parker, L. 2009. Photo-elicitation: An ethno-historical accounting and management research prospect. Accounting, Auditing and Accountability Journal, 22(7): 1111-29.

Parmigiani, A., \& Howard-Grenville, J. 2011. Routines revisited: Exploring the capabilities and practice perspectives. Academy of Management Annals, 5(1): 413-453. 
Pentland, B., \& Feldman, M. 2005. Organizational routines as a unit of analysis. Industrial and Corporate Change, 14(5): 793-815.

Pentland, B.T., \& Feldman, M.S. 2008. Designing routines: On the folly of designing artifacts, while hoping for patterns of action. Information and Organization, 18: 235-250.

Pentland, B.T., \& Reuter, H.H. 1994. Organizational routines as grammars of action. Administrative Science Quarterly, 39: 484-510.

Ployhart, R.E., \& Vandenberg, R.J. 2010. Longitudinal research: The theory, design, and analysis of change. Journal of Management, 36: 94-130.

Rafaeli, A., \& Vilnai-Yavetz, I. 2004. Emotion as a connection of physical artifacts and organizations. Organization Science, 15(6): 671-686.

Reay, T., \& Hinings, C.R. 2009. Managing the rivalry of competing institutional logics. Organization Studies, 30: 629-652

Rerup, C., \& Feldman, M.S. 2011. Routines as a source of change in organizational schema: The role of trial-and-error learning. Academy of Management Journal, 54: 577-610.

Reynaud, B. 2005. The void at the heart of rules: Routines in the context of rule-following. The case of the Paris Metro Workshop. Industrial and Corporate Change, 14: 847-871.

Rumelt, R.P., Schendel, D.E., \& Teece, D.J. 1994. Fundamental Issues in Strategy. Boston: Harvard Business School Press.

Salvato, C. 2009. Capabilities unveiled: The role of ordinary activities in the evolution of product development processes. Organization Science, 20(2): 384-409.

Salvato, C., \& Rerup C. 2011. Beyond collective entities: Multilevel research on organizational routines and capabilities. Journal of Management, 37: 468-490.

Sastry, M.A. 1997. Problems and paradoxes in a model of punctuated organizational change. Administrative Science Quarterly, 42(2): 237-275.

Stene, E. 1940. An approach to the science of administration. American Political Science Review, 34: 1124-1137.

Szulanski, G. 1996. Exploring internal stickiness: Impediments to the transfer of best practice within the firm. Strategic Management Journal, 17: 27-43.

Thornton, P.H., Ocasio, W., \& Lounsbury, M. 2012. The Institutional Logics Perspective: A New Approach to Culture, Structure, and Process. New York: Oxford University Press.

Turner, S.F., Mitchell, W., \& Bettis, R.A. 2013. Strategic momentum: How experience shapes temporal consistency of ongoing innovation. Journal of Management, 39: 1855-1890.

Turner, S.F., \& Rindova, V. 2012. A balancing act: How organizations pursue consistency in routine functioning in the face of ongoing change. Organization Science, 23(1): 24-46.

Uzzi, B., \& Lancaster, R. 2003. Relational embeddedness and learning: The case of bank loan managers and their clients. Management Science, 49(4): 383-399.

Winter, S.G., \& Szulanski, G. 2001. Replication as strategy. Organization Science, 12: 730-743.

Winter, S.G., Szulanski, G., Ringov, D., \& Jensen, R.J. 2012. Reproducing knowledge: Inaccurate replication and failure in franchise organizations. Organization Science, 23(3): 672-685.

Zollo, M., Reuer, J.J., \& Singh, H. 2002. Interorganizational routines and performance in strategic alliances. Organization Science, 13(6): 701-713. 
Table 1

Within and Between Groups Analysis of Participant Actions and Interactions (for Initial and Subsequent Days)

Table 1a: Average Number of Towels Replaced Per Day

\begin{tabular}{|c|c|c|c|c|}
\hline Housekeeper Actions & Control & Treatment & $\begin{array}{c}\text { Between Group } \\
\text { Mean Difference } \\
\text { (Treatment - Control) }\end{array}$ & t-statistic \\
\hline Initial Day (Number of towels replaced) & $\begin{array}{c}0.97 \\
(0.13)\end{array}$ & $\begin{array}{c}1.04 \\
(0.12)\end{array}$ & 0.07 & 0.35 \\
\hline $\begin{array}{l}\text { Subsequent Days (Number of towels } \\
\text { replaced) }\end{array}$ & $\begin{array}{c}1.66 \\
(0.13) \\
\end{array}$ & $\begin{array}{c}0.95 \\
(0.12) \\
\end{array}$ & -0.71 & $4.02^{* * * *}$ \\
\hline $\begin{array}{l}\text { Within Group Mean Difference } \\
\text { (Subsequent days - Initial day) }\end{array}$ & 0.69 & -0.09 & & \\
\hline t-statistic & $3.66^{* * *}$ & 0.51 & & \\
\hline
\end{tabular}

Table 1b: Average Number of Towels Left in the Bathtub Per Day

\begin{tabular}{|c|c|c|c|c|}
\hline Guest Actions & Control & Treatment & $\begin{array}{l}\text { Between Group } \\
\text { Mean Difference } \\
\text { (Treatment - Control) }\end{array}$ & t-statistic \\
\hline $\begin{array}{l}\text { Initial Day (Number of towels left in } \\
\text { the bathtub) }\end{array}$ & $\begin{array}{c}0.53 \\
(0.13)\end{array}$ & $\begin{array}{c}0.20 \\
(0.12)\end{array}$ & -0.33 & $3.17^{* * *}$ \\
\hline $\begin{array}{l}\text { Subsequent Days (Number of towels } \\
\text { left in the bathtub per day) }\end{array}$ & $\begin{array}{c}0.52 \\
(0.09) \\
\end{array}$ & $\begin{array}{c}0.26 \\
(0.06) \\
\end{array}$ & -0.26 & $2.41^{* * *}$ \\
\hline $\begin{array}{l}\text { Within Group Mean Difference } \\
\text { (Subsequent days - Initial day) }\end{array}$ & -0.01 & 0.06 & & \\
\hline t-statistic & 0.05 & 0.82 & & \\
\hline
\end{tabular}

Table 1c: Average Number of Towels Left in Non-Designated Locations Per Day

\begin{tabular}{|c|c|c|c|c|}
\hline Guest Actions & Control & Treatment & $\begin{array}{l}\text { Between Group } \\
\text { Mean Difference } \\
\text { (Treatment - Control) } \\
\end{array}$ & t-statistic \\
\hline $\begin{array}{l}\text { Initial Day (Number of towels left on } \\
\text { non-designated artifacts) }\end{array}$ & $\begin{array}{c}0.32 \\
(0.10) \\
\end{array}$ & $\begin{array}{c}0.32 \\
(0.10) \\
\end{array}$ & 0.00 & 0.01 \\
\hline $\begin{array}{l}\text { Subsequent Days (Number of towels } \\
\text { left per day on non-designated } \\
\text { artifacts) }\end{array}$ & $\begin{array}{c}0.41 \\
(0.09)\end{array}$ & $\begin{array}{c}0.07 \\
(0.03)\end{array}$ & -0.34 & $1.94^{*}$ \\
\hline $\begin{array}{l}\text { Within Group Mean Difference } \\
\text { (Subsequent days - Initial day) }\end{array}$ & 0.09 & -0.25 & & \\
\hline t-statistic & 0.44 & $2.34^{*}$ & & \\
\hline
\end{tabular}

\section{Notes:}

$* * * p<0.001$

$* * p<0.01$

$* p<0.05$,

${ }^{\dagger} p<0.10$ (one-tailed tests)

Values in parentheses are standard errors.

Number of observations: Initial Day (Control Group: 36; Treatment Group: 43) Subsequent Days: 48 (both groups) Degrees of freedom for t-statistic: Between groups (Initial day: 77; Subsequent days: 94); Within groups (Control: 82; Treatment: 89) 
Table 2

Understanding-based Redesign and the Actions of Routine Participants

\begin{tabular}{|c|c|c|}
\hline First-Order Codes and Illustrative Evidence & $\begin{array}{c}\text { Theoretical } \\
\text { Observations } \\
\text { (Second-Order Codes) } \\
\end{array}$ & $\begin{array}{c}\text { Aggregate } \\
\text { Theoretical } \\
\text { Dimensions } \\
\end{array}$ \\
\hline $\begin{array}{l}\text { Use of representational artifacts to understand what actions the hotel wants for towel replacement/reuse } \\
\text { "If there is a sign, then I would use the hamper for replacing the towels. I follow instructions" } \\
\text { "I would use [the basket]. Again I would look to see what the hotel would prefer me to do, and I would probably just } \\
\text { use the basket. It seems like a reasonable thing to do" } \\
\text { "I will glance at the sign, and I will immediately know what it is. I saw the sign when I checked in this hotel" } \\
\text { "[The basket] would be the clue that something is different, because I wouldn't know what that is for. Because it is a } \\
\text { little large for a recycling container, and it's in the bathroom, so what's it doing?... it might've confused me a bit... } \\
\text { maybe I'll read this [sign], and see what I missed" }\end{array}$ & $\begin{array}{l}\text { Use representational } \\
\text { artifacts to understand } \\
\text { what actions are expected } \\
\text { and/or to take their cue to } \\
\text { recall what actions are } \\
\text { expected }\end{array}$ & Interpreting \\
\hline $\begin{array}{l}\text { Use of hook and towel rack for towel reuse based on usage at home } \\
\text { "Because I use the bathroom hook at home. So I think that is just my routine to hang the towel on the hook to dry out, } \\
\text { and it's there for me the next day" } \\
\text { "I would operate the same way I do at home, which means I would just hang it up again" } \\
\text { "Because the nice thing about a towel rack -- you know, same thing with myself in my house and everything -- when } \\
\text { you use a towel like this, you hang it back up" } \\
\text { Use of basket for towel replacement based on usage at home } \\
\text { "It's more conducive to what you're used to at home... From a process standpoint, this is probably how you would do } \\
\text { your laundry at home. It just makes more sense. It's more intuitive" } \\
\text { [It is like] "the way I was brought up. We always had a hamper in our house" } \\
\text { "This is... more "home-y" in the sense that you would put something in a basket if it is soiled, whether it's clothes or } \\
\text { towels" }\end{array}$ & $\begin{array}{l}\text { Draw on previous } \\
\text { experience of using } \\
\text { similar artifacts for similar } \\
\text { purposes in related } \\
\text { settings to understand } \\
\text { what actions are expected }\end{array}$ & Relating \\
\hline $\begin{array}{l}\text { Use and avoidance of particular artifacts (e.g., towel rack, hook) to accomplish intended outcome } \\
\text { "This morning I thought where would I put it in the towel rack. Because if I fold it up, it won't dry. It will just sit there } \\
\text { in a wet folded pile. So I used the hook on the back of the door" } \\
\text { [Regarding using a towel rack] "that's not gonna dry, it might be soggy tomorrow, and then you're not going to use it" } \\
\text { "I probably wouldn't put it back on the rack, because then it wouldn't dry. I probably would've hung it over the [shower } \\
\text { rod]" }\end{array}$ & $\begin{array}{l}\text { - Accomplish a desired } \\
\text { outcome by using } \\
\text { appropriate artifacts }\end{array}$ & Functioning \\
\hline $\begin{array}{l}\text { Use and avoidance of particular artifacts (e.g., basket, towel rack) because of appearance } \\
\text { "I would normally toss my used towels in the corner, you know, underneath. So that if there was a basket, it would be } \\
\text { better" } \\
\text { "Well, now [the towel rack] is not conducive to hanging it up, because... it looks messy" } \\
\text { [Indicated that having the towel rack over the commode] "tends to suggest a lack of appeal" }\end{array}$ & $\begin{array}{l}\text { - Achieve a pleasing } \\
\text { outcome/experience, and } \\
\text { to avoid displeasing ones }\end{array}$ & Rendering \\
\hline $\begin{array}{l}\text { Use of particular artifacts to communicate to housekeepers what guest wants for towel replacement/reuse } \\
\text { "In many hotels, you see something that sounds like [the sign] -- instructing you to put your used towels, or towels you } \\
\text { want exchanged -- put them in the tub. Sometimes it doesn't even say that, but I do it anyway, because I think it sends } \\
\text { a pretty clear message that those need to be replaced, but if you put them on the rack, it doesn't" } \\
\text { "I normally just toss them in the corner because then, to me, that's pretty indicative that I'm not using that towel again" }\end{array}$ & $\begin{array}{l}\text { Convey to other } \\
\text { participants one's own } \\
\text { actions and what actions } \\
\text { are expected in return } \\
\text { from other participants }\end{array}$ & Communicating \\
\hline
\end{tabular}




\begin{tabular}{|l|l|l|}
\hline \multicolumn{1}{|c|}{ First-Order Codes and Illustrative Evidence } & $\begin{array}{c}\text { Theoretical } \\
\text { Observations } \\
\text { (Second-Order Codes) }\end{array}$ & $\begin{array}{c}\text { Aggregate } \\
\text { Theoretical } \\
\text { Dimensions }\end{array}$ \\
\hline "I would put it on the floor, so the girl can't miss it" & \\
"Most of the time on the floor is pretty clear, too" & \\
\hline $\begin{array}{l}\text { Use of particular artifacts (e.g., hook, basket) with other participants and their actions in mind } \\
\text { [By using the hook], the towel has a chance to maybe dry a little bit before somebody picks it up. Because I do feel a } \\
\text { level of guilt if someone has to pick up a wet towel" } \\
\text { "If there is a sign, then I would use the hamper for replacing the towels... It is easy for the housekeeping staff to carry } \\
\text { out the dirty towels." }\end{array}$ & $\begin{array}{l}\text { • Reduce inconvenience to } \\
\text { and/or ease the effort } \\
\text { required of other } \\
\text { participants }\end{array}$ \\
$\begin{array}{l}\text { "When I was a kid, that's just where you always put [the towels] when you were done with them. There were a lot of } \\
\text { times you did it right before you left the room, like if someone needed to use the shower." }\end{array}$ & \multicolumn{1}{c|}{ Facilitating } \\
\hline
\end{tabular}


Figure 1a

Control Group Setting

Save Our Planet

$$
\begin{aligned}
& \text { Dear Guests: } \\
& \text { Everyday millions of gallons of water are used to } \\
& \text { wash towels that have been only used once. }
\end{aligned}
$$

You make the choice:

- A towel on the towel rack means: "I will use again"

- A towel in the bathtub means: "Please exchange"

Please Decide For Yourself

Thank You for Helping Us Conserve

The Earth's Vital Resources
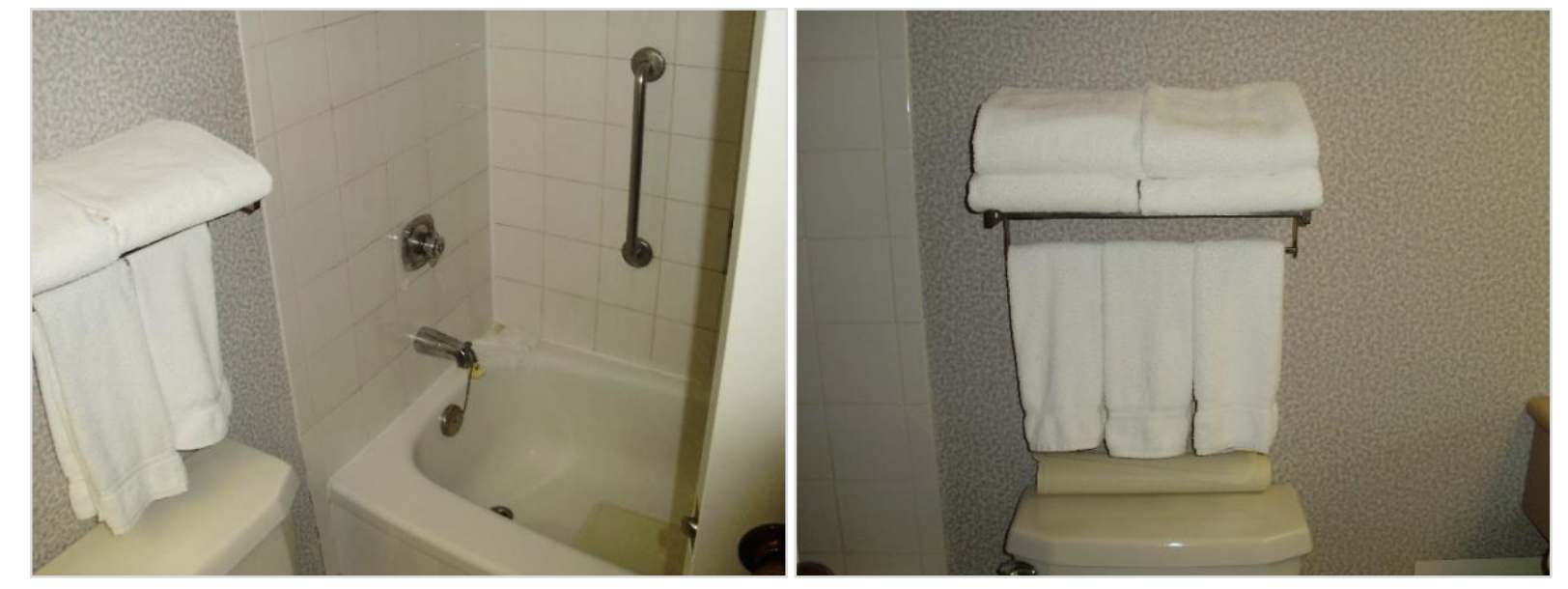

Figure 1b

Treatment Group Setting

\section{Save Our Planet}

$$
\begin{aligned}
& \text { Dear Guests: } \\
& \text { Everyday millions of gallons of water are used to } \\
& \text { wash towels that have been only used once. }
\end{aligned}
$$

You make the choice:

- A towel on the bathroom door hook means: "I will use again"

- A towel in the laundry hamper means: "Please exchange"

Please Decide For Yourself

Thank You for Helping Us Conserve The Earth's Vital Resources

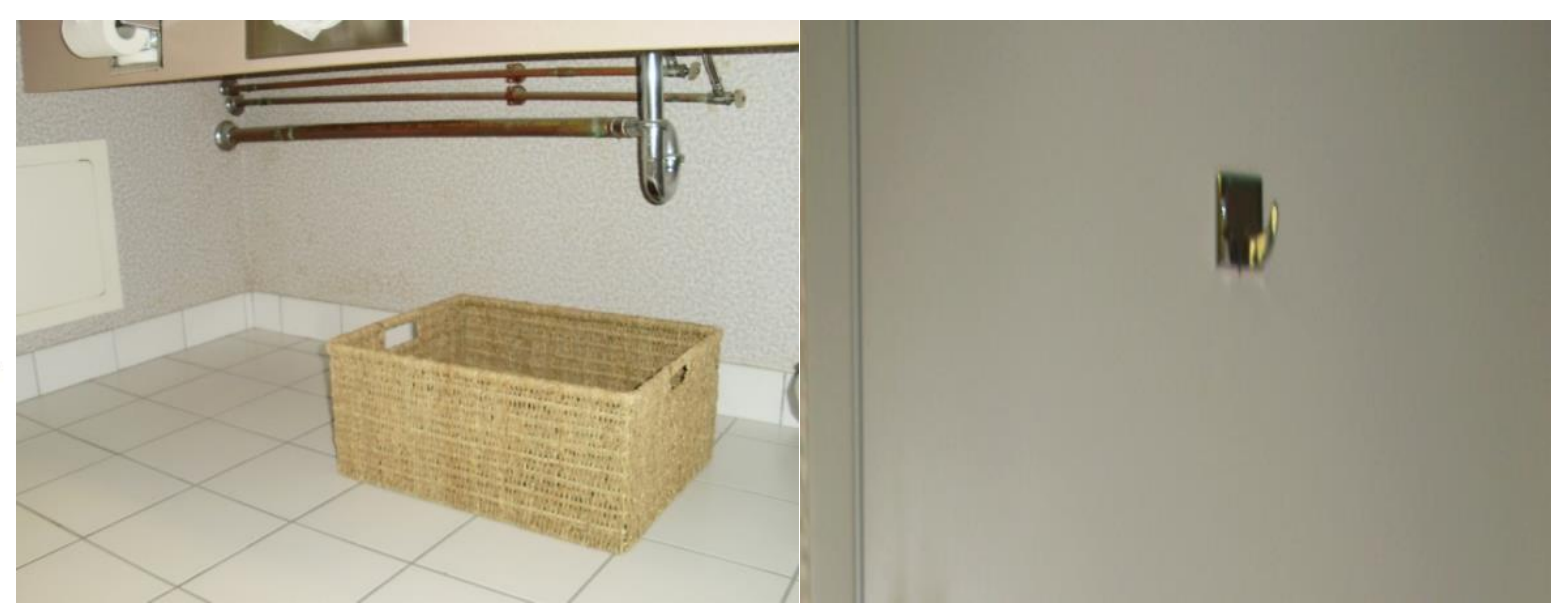


Figure 2

How Understanding-based Redesign Facilitates Participant Actions to Support Routine Effectiveness

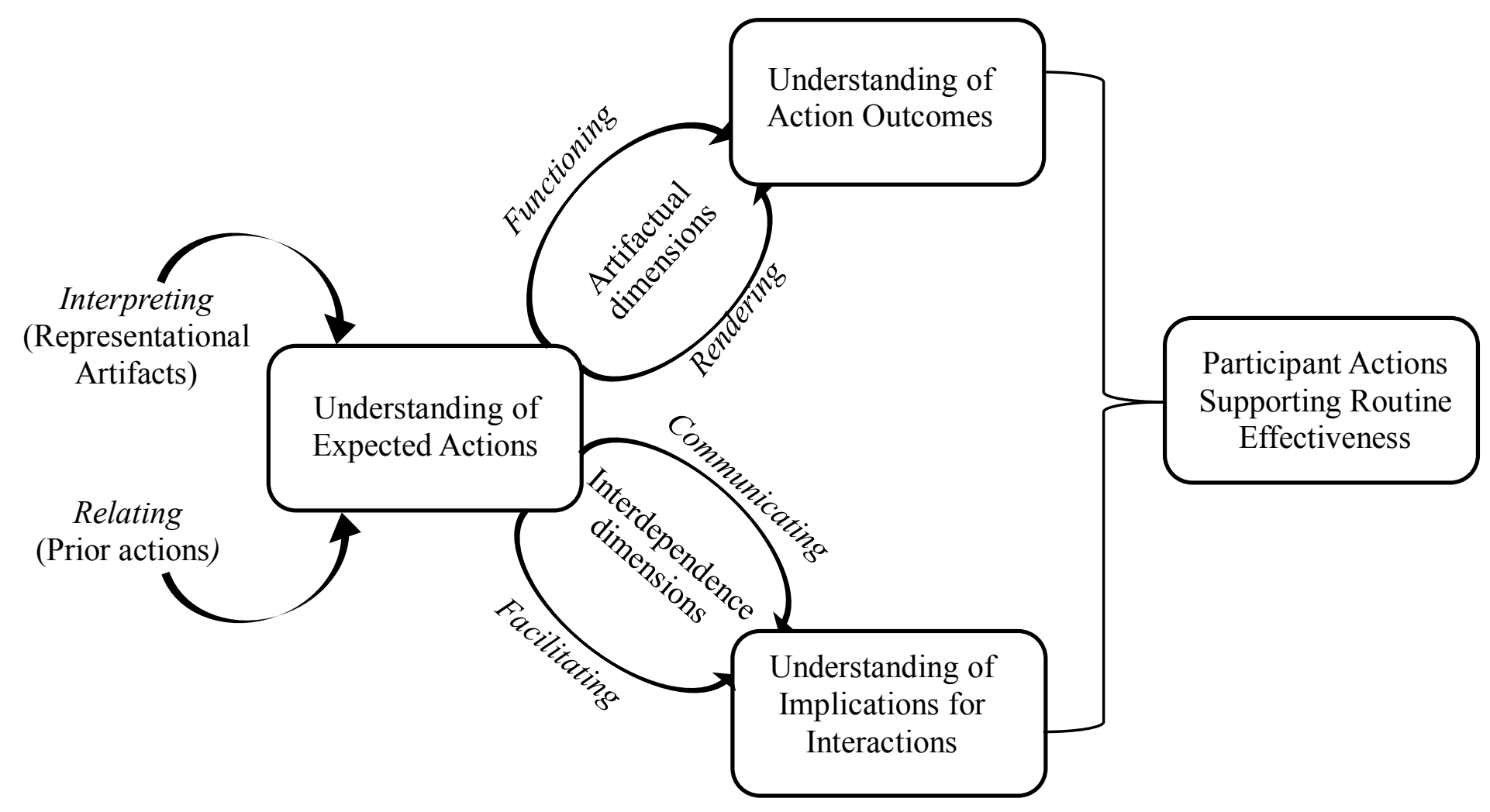

